This item was submitted to Loughborough's Research Repository by the author.

Items in Figshare are protected by copyright, with all rights reserved, unless otherwise indicated.

\title{
The impact of biological bedforms on near-bed and subsurface flow: a laboratory evaluated numerical study of flow in the vicinity of pits and mounds
}

\section{PLEASE CITE THE PUBLISHED VERSION}

https://doi.org/10.1029/2019JF005000

\section{PUBLISHER}

(C) American Geophysical Union

\section{VERSION}

VoR (Version of Record)

\section{PUBLISHER STATEMENT}

An edited version of this paper was published by AGU. Copyright 2019 American Geophysical Union. HAN, X. ... et al, 2019. The impact of biological bedforms on near-bed and subsurface flow: a laboratory evaluated numerical study of flow in the vicinity of pits and mounds. Journal of Geophysical Research: Earth Surface, doi:10.1029/2019JF005000. To view the published open abstract, go to https://doi.org/10.1029/2019JF005000

\section{LICENCE}

CC BY-NC-ND 4.0

\section{REPOSITORY RECORD}

Han, Xu, Hongwei Fang, Matthew F. Johnson, and Stephen P. Rice. 2019. "The Impact of Biological Bedforms on Near-bed and Subsurface Flow: A Laboratory Evaluated Numerical Study of Flow in the Vicinity of Pits and Mounds". figshare. https://hdl.handle.net/2134/38168. 


\section{JGR Earth Surface}

\section{RESEARCH ARTICLE 10.1029/2019JF005000 \\ Key Points: \\ - A novel, unified water-sediment three-dimensional model is developed to investigate the impact \\ The Impact of Biological Bedforms on Near-Bed and Subsurface Flow: A Laboratory-Evaluated Numerical Study of Flow in the Vicinity of Pits and Mounds} of simulated biogenic bedforms

- The impact of biogenic bedforms on near-bed turbulence and sediment entrainment is discussed in gravelly substrates

- Biogenic bedform morphology has an important role in determining the spatial extent of up- and down-welling flow

Supporting Information:

- Supporting Information S1

- Figure S1

Correspondence to:

H. W. Fang,

fanghw@mail.tsinghua.edu.cn

Citation:

Han, X., Fang, H. W., Johnson, M. F., \& Rice, S. P. (2019). The impact of biological bedforms on near-bed and subsurface flow: A laboratory-evaluated numerical study of flow in the vicinity of pits and mounds. Journal of Geophysical Research: Earth Surface, 124, 1939-1957. https://doi.org/ 10.1029/2019JF005000

Received 7 JAN 2019 Accepted 21 JUN 2019 Accepted article online 1 JUL 2019 Published online 24 JUL 2019

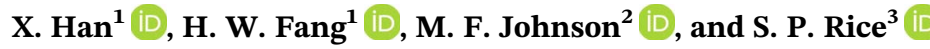 \\ ${ }^{1}$ State Key Laboratory of Hydro-science and Engineering, Department of Hydraulic Engineering, Tsinghua University, \\ Beijing, China, ${ }^{2}$ School of Geography, University Park, University of Nottingham, Nottingham, UK, ${ }^{3}$ Department of \\ Geography, Loughborough University, Loughborough, UK
}

\begin{abstract}
The complex surface topography of river substrates controls near-bed hydraulics and drives the exchange of subsurface and surface flow. In rivers, the topographic structures that are studied are usually formed by the flow, but it is known that many animals also create biogenic bedforms, such as pits and mounds. Here, a large-eddy simulation model of flow over a pit and a mound is evaluated with flume experiments. The model includes actual bedform topography, and the topographic complexity of the surrounding bed surface. Subsurface grains are organized in a body-centered cubic packing arrangement. Model evaluation showed strong agreement between experimental and modeling results for velocity $\left(R^{2}>\right.$ $0.8)$ and good agreement for Reynolds stresses $\left(R^{2}>0.7\right)$, which is comparable to other similar studies. Simulation of the pit shows that the length of the downwelling region is smaller than the upwelling region and that the velocity magnitude is higher in the downwelling region. Simulation of the mound reveals that the flow is forced into the bed upstream of the mound and reemerges near the top of the mound. The recirculation zone is limited at the leeside of the mound. With increasing Reynolds number, the depth of the upwelling region at the leeside of the mound increases. The analysis of shear stress indicates that sediments on the upstream edge of the pit and on the downstream face of the mound are relatively unstable. These results demonstrate the effect of biogenic structures on the near-bed flow field, hyporheic exchange, and sediment stability.
\end{abstract}

\section{Introduction}

River substrates are highly heterogeneous at a range of spatial scales, creating a topographically complex environment (Nikora \& Rowinski, 2008; Rice et al., 2014; Sarkar et al., 2016). Topographic features range from individual grains or clusters of grains that protrude into the flow (Hassan \& Reid, 1990; Heritage \& Milan, 2009; Lacey \& Roy, 2007) to bedforms incorporating many sediment grains, such as ripples and dunes (Elliott \& Brooks, 1997; Keshavarzi et al., 2012; Vanoni, 1975), and width-scale undulations in the bed surface (i.e., riffle-pool units; Hein \& Walker, 1977; Marion et al., 2002; Tonina \& Buffington, 2007; Tubino et al., 1999). The presence of bedforms significantly influences mean and turbulent flow conditions with implications for solute transfer and sediment dynamics (Best, 2005; Blois et al., 2014; Dinehart, 1992; Huettel \& Gust, 1992). The majority of research on bedforms in rivers has focused on features generated by the flow and in isolation from ecological processes. However, organisms living on and within river sediments alter substrate topography (Hassan et al., 2008; Tonina \& Buffington, 2009) and structure (Johnson et al., 2011; Pledger et al., 2017; Statzner et al., 2000), with implications for near-bed hydraulics (Murray et al., 2002).

The impact of sediment reworking by organisms in sedimentary environments characterized by fine clastic materials has been studied more extensively than it has in gravelly substrates (Friedrichs \& Graf, 2009; Meysman et al., 2006). When sediment is fine, such as in many coastal and estuarine areas, structures formed by invertebrate organisms, such as tubes, tracks, mounds, and pits, can dominate the surface roughness where the surrounding area is predominately flat and fine grained (Volkenborn \& Reise, 2006). In these areas, biogenic bedforms have been shown to have a significant impact on nutrient cycling and the oxygenation of sediments through promotion of exchange between surface and subsurface water (Volkenborn et al., 
2010). In particular, the irrigation of burrows actively by animals and passively through pressure differences across bedform morphology affects metabolic processes occurring within interstitial spaces in sediment (Peine et al., 2009).

When modeling near-bed hydraulics in fine-grained sediments, it may be acceptable that the grain roughness and the bed permeability are ignored or simplified (Best, 2005; Constantinescu et al., 2013; Friedrichs \& Graf, 2009; Kleinhans, 2004; Orvain, 2005). However, for research on gravel beds, the flow and mass exchange between overlying water and subsurface flow can be significantly influenced by bed roughness and permeability (Blois et al., 2012; Harnanan et al., 2015; Higashino, 2013; Inoue \& Nakamura, 2011). Most previous numerical studies of gravel beds predict the spatial distribution of streambed pressure as a function of channel hydraulics as modified by bed topography, with pressure then used to drive a Darcy model for subsurface flow (Kondolf, 2000; Nakamura \& Stefan, 1994; Qian et al., 2009; Tonina \& Buffington, 2007). In these cases, the water and sediment are separated, and, as such, important information about the exchange of momentum at the sediment-water interface may be lost. In addition, most predictions of engineering flows are obtained by the Reynolds-averaged-Navier-Stokes approach, in which instantaneous flow cannot be obtained (Bardini et al., 2012; Higashino et al., 2009).

Studies have summarized the flow patterns around simple geometric shapes in classical hydraulic engineering (Graf \& Istiarto, 2002; Hunt et al., 1988; Muzzammil \& Gangadhariah, 2003; Schlichting, 1980), but the lack of high-resolution data meant these studies were mainly based on simplified topographies without also considering grain roughness and bed permeability. Higher-resolution flow data from acoustic Doppler velocimetry (ADV), particle image velocimetry, and topography from laser scanners and photographic techniques have enabled improved quantification of the flow around complex structures, also considering subsurface exchange processes (Butler et al., 2002; Friedrichs \& Graf, 2009; Roy et al., 2002). For example, Blois et al. (2014) used a simplified geometry comprising six layers of uniform spheres in a laboratory flume and an endoscopic particle image velocimetry system to obtain subsurface flow measurements. They found the flow downstream of coarse-grained bedforms on permeable beds was different to that over impermeable beds (Blois et al., 2014). Despite this significant advance, the regularly arranged spheres used were not representative of typical bed roughness, and subsurface flow was able to penetrate through straight passageways between grains, formed by the regular packing of spheres (Blois et al., 2014). A distinction between the diameter of gravel in the bedform and the surrounding substrate may also have caused unrealistic flow exchange processes. In addition, Cooper et al. (2018) studied the flow over water-worked gravel topography. They compared permeable and completely impermeable surfaces. The impact on surface flows is demonstrated while the impact on subsurface flows is still unclear. Such hyporheic flow plays important roles in biochemical exchanges in the river bed, including oxygenation of the bed and removal of waste products for incubating salmonid eggs (Cardenas et al., 2017; Claret et al., 2010). Understanding the hydrodynamic process of surface water-groundwater exchange can provide a fundamental basis for more complex biochemical reactions. Questions remain about modeling and measuring flow exchange processes around topographic structures in gravel beds, particularly those associated with living organisms. The specific objectives of the present paper were to (1) develop and apply a novel large eddy simulation (LES) model that is able to simulate simultaneously subsurface flow and surface flow over a pit and the mound; (2) evaluate the LES model of the flow at representative positions using physical measurements along a simple transect in a laboratory flume; (3) analyze the near-bed flow heterogeneity and the water exchange between surface and subsurface flow; and (4) estimate the impacts of topographic changes on grain entrainment. The experiments focus on pits and mounds because tracks and tubes are unlikely to be present in coarse, noncohesive material. Pits and mounds are constructed in gravel bedded rivers in a range of sediment grain sizes from fine gravels to cobbles by crayfish (Johnson et al., 2010, 2011), spawning salmon and trout (Hassan et al., 2008), lamprey (Hogg et al., 2014), barbel (Pledger et al., 2017), and many other freshwater fish (Herrington \& Popp, 2004; Vives, 1990; Wallin, 1992), including Nocomis micropogin that build spectacular dome-shaped nests comprising up to 10,000 individual gravel particles (Lachner, 1952; Sabaj et al., 2000). These organisms can be important geomorphic agents in gravel bed rivers and riparian areas (Butler, 2002; Rice et al., 2012; Statzner et al., 2000). In the LES model, surface topography data from flume experiments were used, and the inner bed was modeled by packing spheres with the same bed permeability as measured in the flume. As there is no artificial boundary at the sediment-water interface, both hydrostatic and hydrodynamic flows were modeled, and the flow exchange was predicted. 


\section{Methods}

\subsection{Experimental Method and Setup}

Physical measurements were obtained in a glass-walled, tilting, 0.6-m-wide, 8-m-long laboratory flume in the Department of Geography, Loughborough University (Figure 1). The grain size used in experiments was narrowly graded gravel of 5-11 $\mathrm{mm}$ in $b$-axis diameter because it is known that crayfish are active on substrates of this size in rivers (Johnson et al., 2014), that crayfish construct pits and mounds in material of this size (Johnson et al., 2010), and that this size of gravel was unlikely to be mobilized in the flows used in the experiments. The modeled and measured results therefore have a 1:1 scale. The gravel was predominately bladed (Sneed \& Folk, 1958) and well rounded (0.8; Krumbein, 1941). The density of the grain was taken as $2,650 \mathrm{~kg} / \mathrm{m}^{3}$. The experimental area of the flume was filled with gravel and screeded flat to a bed depth of $0.1 \mathrm{~m}$. Upstream and downstream of the experimental section, roughness boards were used to generate a boundary layer. These were constructed from river gravels (5- to 35-mm $b$-axis diameter) fixed to boards and positioned, so their surface was flush with that of the loose gravels. Fixed boards ensured that incoming hydraulic conditions were consistent between runs.

In the experimental section, the two kinds of artificial bed structures, a pit and a mound, were constructed by hand to the dimensions recorded in Johnson et al. (2010) study of crayfish pits and mounds after $24 \mathrm{hr}$ of activity. As such, pits were circular dishes with a diameter of $135 \mathrm{~mm}$ and a maximum depth of $20 \mathrm{~mm}$. Mounds were also circular, with a diameter of $140 \mathrm{~mm}$ and a maximum elevation above the bed of 20 $\mathrm{mm}$. Each feature was positioned in the centerline of the flume.

The bed porosity $(\varphi)$ was 0.357 and was calculated using the water displacement method in a transparent container of $0.61 \mathrm{~m} \times 0.37 \mathrm{~m} \times 0.12 \mathrm{~m}$.

\subsection{Flow Conditions}

To investigate the effects of flow velocity on near-bed and subsurface flow, two flow conditions were adopted: a "high" flow and a "low" flow (Table 1). Each flow condition was used for each bed structure. The conditions used are a simplification of river flows but are comparable in bulk statistics to small streams; for example, the Froude number at the low-flow condition approximates pools in the work of Hilldale (2007), and the higher flow approximates glides. At the beginning of each run, the flume channel was slowly filled with water, ensuring no disturbance to the bed or bedform. According to the Shields diagram and logarithmic velocity distribution, the velocity for both runs is much slower than the critical erosion velocity (around $1 \mathrm{~m} / \mathrm{s}$ ).

An ADV was used to measure the flow in all flume runs. The ADV was used to measure three velocity profiles, each containing measurements at five depths. The measurement depths were 2, 5, 8, 10, and $15 \mathrm{~cm}$ above the substrate surface, and each record was $2 \mathrm{~min}$ long at 100-Hz recording frequency. The profiles were at $15-\mathrm{cm}$ upstream of the centerpoint of the bedform, $15-\mathrm{cm}$ downstream from the bedform, and directly over the centerpoint of the bedform. The three profiles were located at the most representative positions where accelerating, decelerating, and recirculating flow occurred. This information was used to evaluate the modeling results at these key locations. The sampling volume diameter of the ADV was $6 \mathrm{~mm}$, and the sampling volume height was $7 \mathrm{~mm}$. The total sampling volume was approximately $0.2 \mathrm{~cm}^{3}$. Signal-to-noise ratio was maintained above $15 \mathrm{~dB}$ or greater, and correlations were greater than $90 \%$ above $5 \mathrm{~cm}$ from the bed and greater than $80 \%$ nearest the bed in both flow conditions.

The shear velocity, $u_{*}$, obtained from the velocity and Reynolds shear stress (RSS) profiles, was used to scale the turbulent quantities. The RSS profiles were extended linearly to the bed surface to determine $u_{*}$ as 0.0093 and $0.0206 \mathrm{~m} / \mathrm{s}$ for low- and high-velocity conditions, respectively. Values of $u_{*}$ were also determined from the ratio of the velocity slope as 0.0088 and $0.0187 \mathrm{~m} / \mathrm{s}$, respectively, providing similar estimates and increasing confidence in the estimates.

\subsection{Topographic Characterization}

After each experimental run, the flume was slowly drained, taking care not to disturb sediment grains. Then the bedform and surrounding substrate were photographed. A digital elevation model (DEM) of the bed surface was generated from these photographs using Structure from Motion (SfM). This technology is widely used in reconstructing three-dimensional models from images (Szeliski, 2011; Tang et al., 2018). In both 


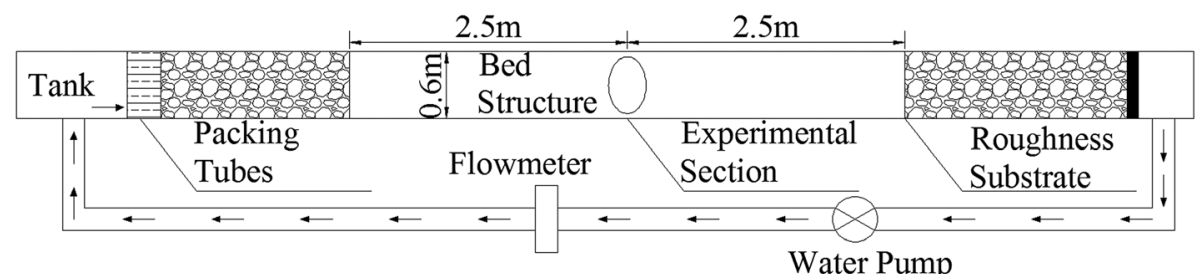

Figure 1. Schematic of the flume setup. The image is a top view of the flume. The roughness substrate corresponds to the gravel with the diameter of $25-35 \mathrm{~mm}$, and the diameter of gravel in the experimental section is $5-11 \mathrm{~mm}$.

runs, at least 12 ground control points were placed around the bed structures. The spatial positons of the ground control points in the Cartesian coordinates were also measured by a point gauge. The focal length of the camera was $29 \mathrm{~mm}$, and the resolution of the photos was 3,264 $\times 2,448$ pix. Parallel photos were taken with a $40 \%$ side and forward overlap. The error of the reconstructed DEM was approximately $4 \mathrm{~mm}$.

\subsection{Numerical Method}

A LES model called Hydro3D, which is able to simulate simultaneously subsurface flow and surface flow in one numerical scheme, was used for the simulations of flow through and over pits and mounds. Hydro3D has been evaluated for and applied to several complex flows, including the flow over rough and permeable beds (Bomminayuni \& Stoesser, 2011; Fang et al., 2018; Han et al., 2018; Kara et al., 2015; Stoesser \& Nikora, 2008). The solute transfer and flow exchange across the sediment-water interface were also successfully predicted by the LES model. The dimensionless LES equations obtained by filtering of the incompressible Navier-Stokes equations can be written as

$$
\begin{gathered}
\frac{\partial u_{i}}{\partial x_{i}}=0 \\
\frac{\partial u_{i}}{\partial t}+\frac{\partial u_{i} u_{j}}{\partial x_{j}}=-\frac{\partial p}{\partial x_{j}}+\frac{\partial\left(2 v S_{i j}\right)}{\partial x_{j}}-\frac{\partial \tau_{i j}}{\partial x_{j}}
\end{gathered}
$$

where $u_{i}$ and $u_{j}$ are the $i$ th and $j$ th components of the resolved instantaneous velocity vector ( $i$ or $j=1,2,3$ ); $x_{1},, x_{2}$ and $x_{3}$ represent the spatial location vectors in the $x, y$, and $z$ directions, respectively; $p$ is the resolved pressure divided by the density; $v$ is the kinematic viscosity; and $S_{i j}$ is the strain rate tensor, $S_{i j}=1 / 2\left(\partial u_{i} / \partial x_{j}\right.$ $\left.+\partial u_{j} / \partial x_{i}\right)$. The subgrid scale stress $\tau_{i j}$ results from filtering of the nonlinear convective fluxes, which is defined as $\tau_{i j}=-2 v_{t} S_{i j}$. In this study, the subgrid scale viscosity $v_{t}$ is computed from the wall-adapting local eddy viscosity proposed by Nicoud and Ducros (1999) as follows:

$$
v_{t}=\left(C_{w} \Delta\right)^{2} \frac{\left(s_{i j}^{d} s_{i j}^{d}\right)^{3 / 2}}{\left(S_{i j} S_{i j}\right)^{5 / 2}+\left(s_{i j}^{d} s_{i j}^{d}\right)^{5 / 4}}
$$

Table 1

Flow Parameters for Both Runs in the Flume Experiment

\begin{tabular}{lcc}
\hline Flow parameters & Low velocity & High velocity \\
\hline Water depth, $h(\mathrm{~m})$ & 0.225 & 0.230 \\
Discharge, $\mathrm{Q}\left(\mathrm{m}^{3} / \mathrm{s}\right)$ & 0.012 & 0.024 \\
Bulk velocity, $U_{b}(\mathrm{~m} / \mathrm{s})$ & 0.089 & 0.174 \\
Bulk Reynolds number, $\mathrm{Re}_{\mathrm{b}}$ & 20,000 & 40,000 \\
Froude number, Fr & 0.06 & 0.12 \\
\hline
\end{tabular}

Note. The bulk Reynolds number $\operatorname{Re}_{\mathrm{b}}$ is defined as $U_{b} h / v$, where $U_{b}$ is the bulk velocity, $h$ is the flow depth, and $v$ is the coefficient of kinematic viscosity of the fluid. where $C_{w}=0.46$ and $\Delta=(\Delta x \Delta y \Delta z)^{1 / 3}$. The traceless symmetric part of the square of the velocity gradient is computed as

$$
s_{i j}^{d}=\frac{1}{2}\left(g_{i k} g_{k j}+g_{j k} g_{k i}\right)-\frac{1}{3} \delta_{i j} g_{k k}^{2} \text { with } g_{i j}=\frac{\partial u_{i}}{\partial x_{j}}
$$

Finite differences method was used to discretize the governing equations on a staggered Cartesian grid. The convection and diffusion terms were approximated by fourth-order accurate central differences (Kampanis \& Ekaterinaris, 2006). An explicit three-step Runge-Kutta scheme was used to integrate the equations in time, providing second-order accuracy. Within the time step, convection and diffusion terms were solved explicitly in a predictor step, which was followed by a corrector step during 


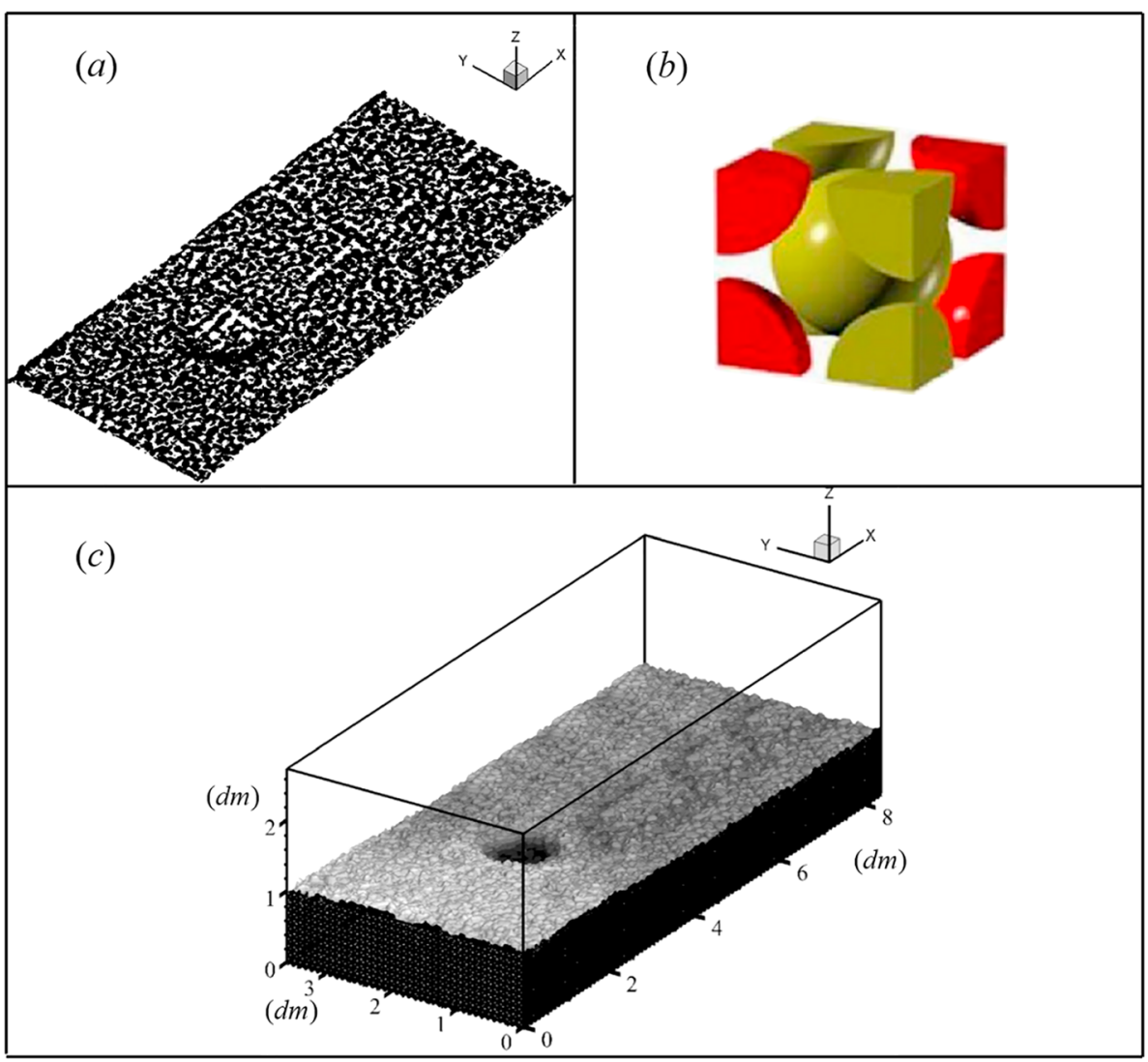

Figure 2. (a) The permeable bed surface used in the simulation. The digital elevation model is generated by structure from motion, and the porosity of the surface is 0.357 . (b) The basic repeating domain of body-centered cubic packing spheres used in the bed. The diameter of sphere is $8 \mathrm{~mm}$, and the porosity of the domain is 0.357 . (c) Computational setup of the permeable bed with reproduced bed roughness on the surface and packing spheres in the subsurface. The flow depth is around $0.18 \mathrm{~m}$, and the bed thickness is around $0.1 \mathrm{~m}$. The length of the area is $0.84 \mathrm{~m}$, and the width is $0.36 \mathrm{~m}$.

which the pressure and divergence-free-velocity fields were calculated by Poisson equation (Cevheri et al., 2016). Since the outer contour of the elements (included in the roughness and permeable bed) intersected with the grid lines, the direct forcing immersed boundary method was incorporated in the LES model (Peskin, 1972). The details of the immersed boundary method treatment were available in Fang et al. (2014).

\subsection{Numerical Experiments and Bed Configuration}

To reproduce the gravel bed structures present in the physical modeling, the numerical gravel bed was divided into two parts. One part was the bed surface, which contains information about grain-scale roughness and topography (i.e., the pit and the mound). The other part is the subsurface, which contains information about the bed permeability. The DEM of the bed surface was used to generate topography in the numerical model. To make the surface permeable, a moving average method was used, and the porosity of the surface was set to 0.357 , equal to the porosity of the subsurface (Figure 2a). It is difficult to get spatial information, such as packing arrangements, for the subsurface because the grains are not visible and direct measurements are destructive. Therefore, to generate subsurface grain arrangements, and to simplify the bed for simulation, body-centered cubic packing spheres were chosen to simulate an idealized permeable bed (Figure 2b). Importantly, this approach avoids pore spaces aligning in straight tubes, which arises from simpler cubic packing arrangements (Blois et al., 2014; Dybbs \& Edwards, 1984; Horton \& Pokrajac, 2009; Manes et al., 2009; Sinha et al., 2017). The intrinsic porosity of the body-centered cubic packing domain is 0.3108 , and the intrinsic diameter of the sphere is $D_{i}$. To make it more similar to the real bed used in physical experiments, $D_{i}$ was reduced to $0.981 D_{i}$, which leads to a porosity of 0.357 , and $D$ is $8 \mathrm{~mm}$, which is the median diameter of the gravels used in experiments. Using the bed surface as an upper limitation, the two parts were combined together, as shown in Figure 2c. 
Table 2

Computational Geometry for Simulations

\begin{tabular}{llll}
\hline Computational scale $(\mathrm{mm})$ & Domain numbers & Number of points & Grid spacing \\
\hline$x \times y \times z$ & $x \times y \times z$ & $x \times y \times z$ & $\Delta x^{+}, \Delta y^{+}, \Delta z^{+}$ \\
$840 \times 360 \times 272$ & $14 \times 6 \times 3$ & $840 \times 360 \times 272$ & $26 \sim 53$ \\
\hline
\end{tabular}

The scales of the computational domain are shown in Table 2. The same bulk Reynolds numbers recorded in the physical experiments $\left(R e_{b}=20,000\right.$ and 40,000$)$ were adopted in the numerical simulation. The code was parallelized using a message-passing interface and the domain-decomposition technique. The uniform spacing of the grids was $1 \mathrm{~mm}$, and the dimensionless one was $\Delta x^{+}, \Delta y^{+}, \Delta z^{+}=(\Delta x, \Delta y, \Delta z) \times u * / v$, where $u_{*}=$ $(\tau / \rho)^{0.5}$ is the shear velocity and $\tau=h \mathrm{~d} p / \mathrm{d} x$ and $\mathrm{d} p / \mathrm{d} x$ are the pressure gradient driving the flow. The bed thickness $(H)$ is $0.1 \mathrm{~m}$, which is around 12 times the diameter of spheres. The flow depth $(h)$ is $0.18 \mathrm{~m}$, which is defined as the vertical distance from the crest of the roughness elements to the free surface. Cyclic boundary conditions were used in the streamwise and the spanwise directions. The free surface was set as a frictionless rigid lid and treated as a plane of symmetry. The Froude numbers of the experiment are 0.06 and 0.12 for two kinds of flow conditions, which are much smaller than 1 , so the treatment of free surface is applicable. In Figure 3, autocorrelations of streamwise and vertical velocity, $R_{u^{\prime} u^{\prime}}$ and $R_{w^{\prime} w^{\prime}}$, are used to check if the domain is large enough. The data are taken along the streamwise and spanwise direction at the elevation about $5 \mathrm{~cm}$ above the bed surface. The correlations decrease to zero within $0.1 \mathrm{~m}$, so the computational area is large enough to include all scales of vortices concerned. The simulation was initially run for 10 flow throughs to establish fully developed turbulence. One flow through was defined as the length of the computational area $(0.84 \mathrm{~m})$ divided by the bulk velocity $\left(U_{b}\right)$. Then the simulation was continued for another 30 flow throughs to collect turbulence statistics.

\section{Results}

\subsection{Evaluation of the LES Model}

To evaluate the numerical model, velocity profiles were extracted at the same location as in the measured data under both flow conditions. The sampling volume of the ADV was about $0.2 \mathrm{~cm}^{3}$, which contains about

(a)

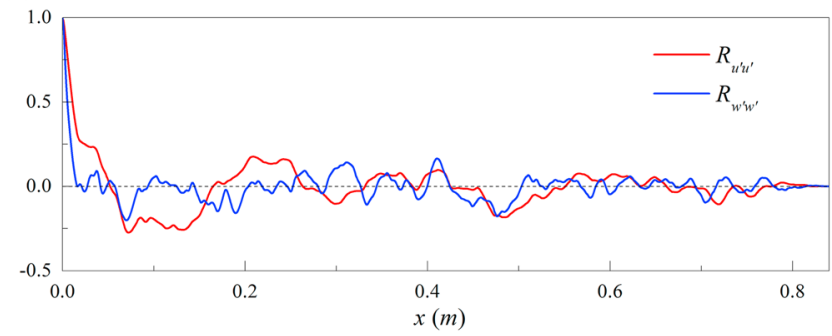

(b)



Figure 3. The autocorrelation of streamwise and vertical velocity components, $R_{u^{\prime} u^{\prime}}$ and $R_{w^{\prime} w^{\prime}}$, which is taken along the (a) streamwise and (b) spanwise direction at the elevation about $5 \mathrm{~cm}$ above the bed surface. 200 grid units in the simulation. If the data in only one grid unit are used to compare with the experimental data, the near-bed Reynolds normal stress will be systematically overpredicted because the variance of Reynolds normal stress inside the averaging volume is large and the near-bed sampling grid cells may be affected by the protruding gravels (see the supporting information). To make a better comparison between the experimental and simulated data, we adopted a moving averaged of a cylinder with the same size as the sampling volume of ADV along each velocity profile of LES. The modeled and measured mean velocity and Reynolds normal stress are shown in Figures 4 and 5. In Figure 4, the measured profiles of streamwise mean velocity are compared with the results of LES. In both cases, there is a good overall agreement with a coefficient of determination of 0.89 and 0.88 in flow conditions with low- and highflow velocity for the pit and 0.87 and 0.85 for low- and high-flow velocity with the mound. In addition, for the pit, the velocity profiles located upstream and downstream show positive values near the bed, while the streamwise velocity is negative around $z / h=-0.1$ in the center of the pit due to the strong recirculation zone. For the mound, the small negative value above the mound top is caused by the small recirculation zone inbetween two gravel grains located on top of the mound. In general, the pit caused less flow disturbance than the mound, evidenced by the fact velocity profiles from the three positions are more similar over the pit than those over the mound. 

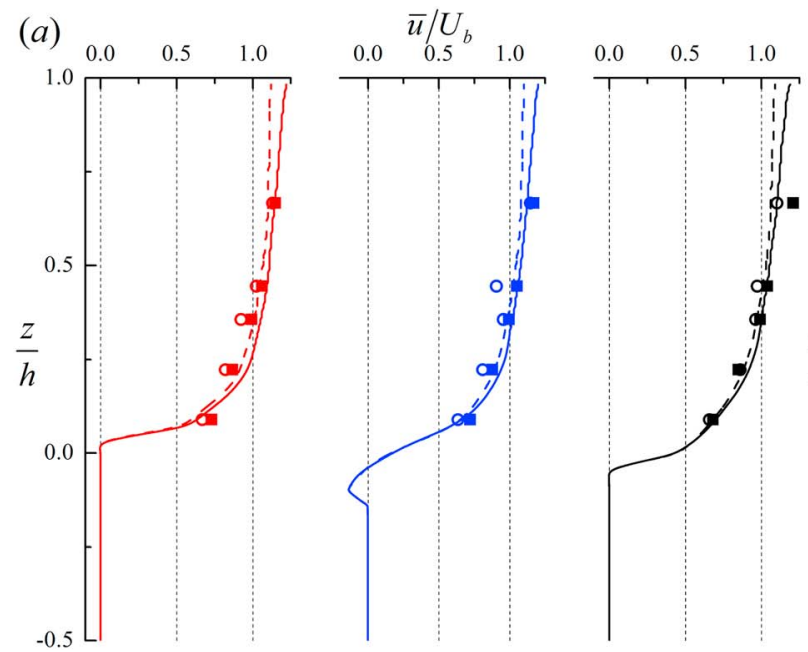

(b)
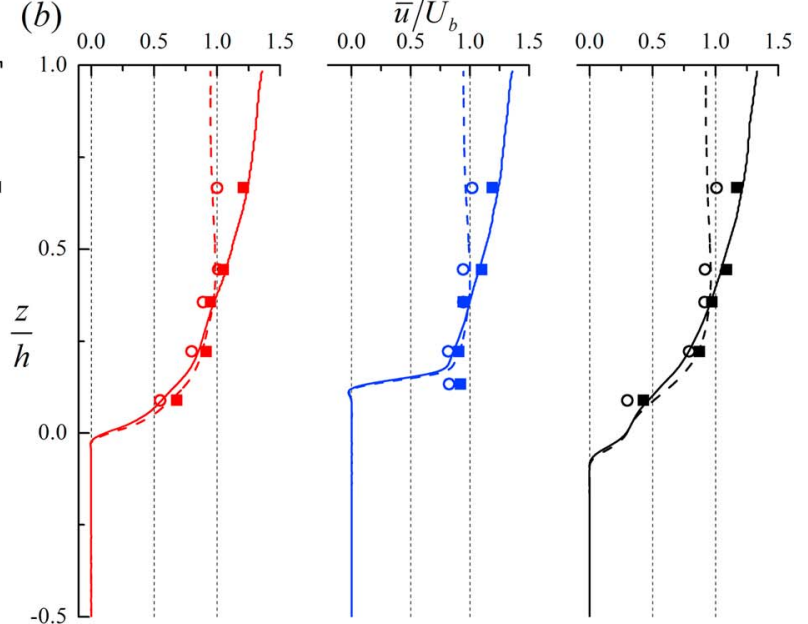

Figure 4. The mean simulated velocity profiles for low (dashed lines) and high (solid lines) flow velocity. The points are comparable to measured velocities for low (open) and high (filled) flow velocity, $15 \mathrm{~cm}$ upstream of the bedform (red), above the center of the bedform (blue), and $15 \mathrm{~cm}$ downstream of the bedform (black) for (a) the pit and (b) the mound.

The profiles of normalized Reynolds normal stress are compared between experimental and numerical results. A coefficient of determination is 0.72 and 0.69 in flow conditions with low- and high-flow velocity for the pit and 0.72 and 0.74 in equivalent conditions for the mound. While weaker than the prediction of velocity, the coefficients are higher than those obtained in similar studies (Sinha et al., 2017) and represent the difficulty in modeling the inherent variability in high-order, near-bed flow quantities. Divergence between measured and modeled values may be caused by highly nonuniform flow around the bed roughness. However, the tendency for Reynolds normal stress to increase when it is closer to the bed is similar. As shown in Figure 5, for the pit, the highest Reynolds normal stress is caused by the shear layer located between the recirculation zone in the pit and the overlying flow.

\subsection{Numerical Results-Surface Flow}

Mean flow velocity (Figure 6a) follows the expected trend over a depression with decreasing velocity over the pit surface and a recirculation zone inside the pit (Yager et al., 1993), with the velocity in the recirculation zone an order of magnitude slower than the free stream, consistent with previous studies (Abelson \&
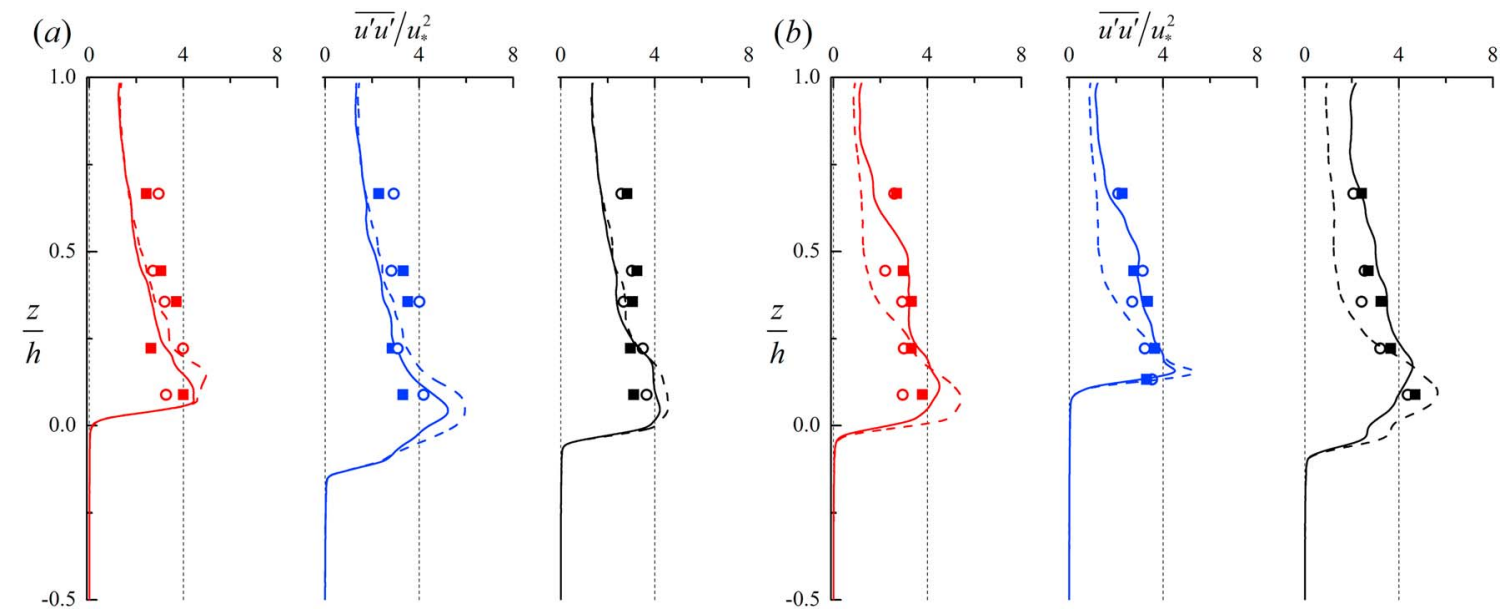

Figure 5. The simulated streamwise Reynolds normal stress for low (dashed lines) and high (solid lines) flow velocity. The points are comparable calculated values for low (open) and high (filled) flow velocity from measured data, $15 \mathrm{~cm}$ upstream of the bedform (red), above the center of the bedform (blue), and $15 \mathrm{~cm}$ downstream of the bedform (black) for (a) the pit and (b) the mound. 

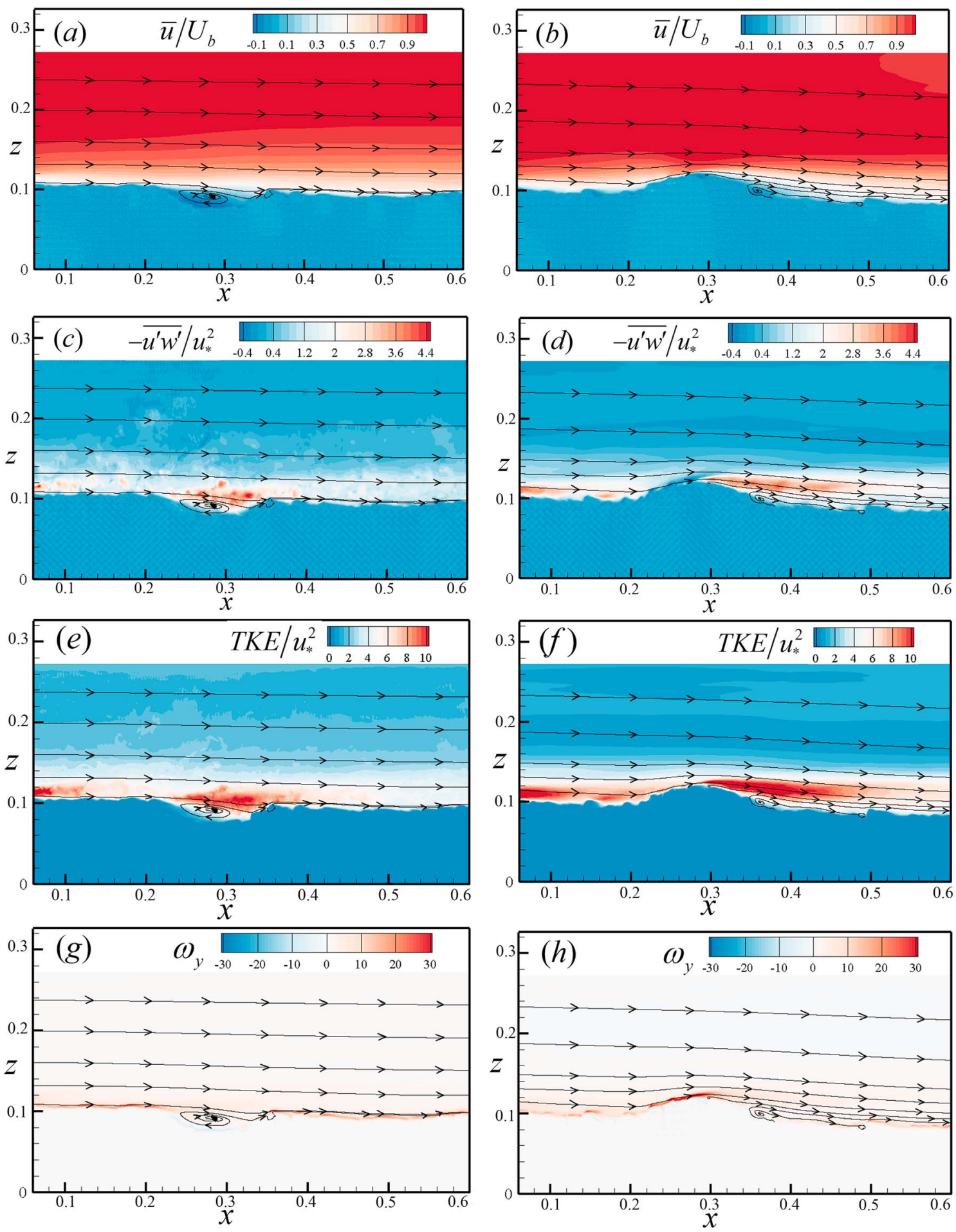

Figure 6. Contours and streamlines of mean streamwise velocity ( $a$ and b), Reynolds shear stress (c and d), turbulent kinetic energy (TKE; e and f), and out-of-plane vorticity ( $\mathrm{g}$ and $\mathrm{h}$ ) for the pit (a, c, e, and $\mathrm{g}$ ) and the mound ( $\mathrm{b}, \mathrm{d}, \mathrm{f}$, and $\mathrm{h}$ ) in low flow velocity. The $x$ and $z$ are both in meter. Equivalent figures for high flow are presented in the supporting information.

Denny, 1997). Mean flow accelerates over the stoss side of the mound (Figure 6b), with flow separation or deceleration from the leeside of the mound. The RSS is high around the separation line, which is attributed to the high-velocity gradient between the recirculation zone inside the pit and the overlying flow (Figure 6c). In addition, some protruding gravels also cause the higher RSS within the corresponding region, such as 


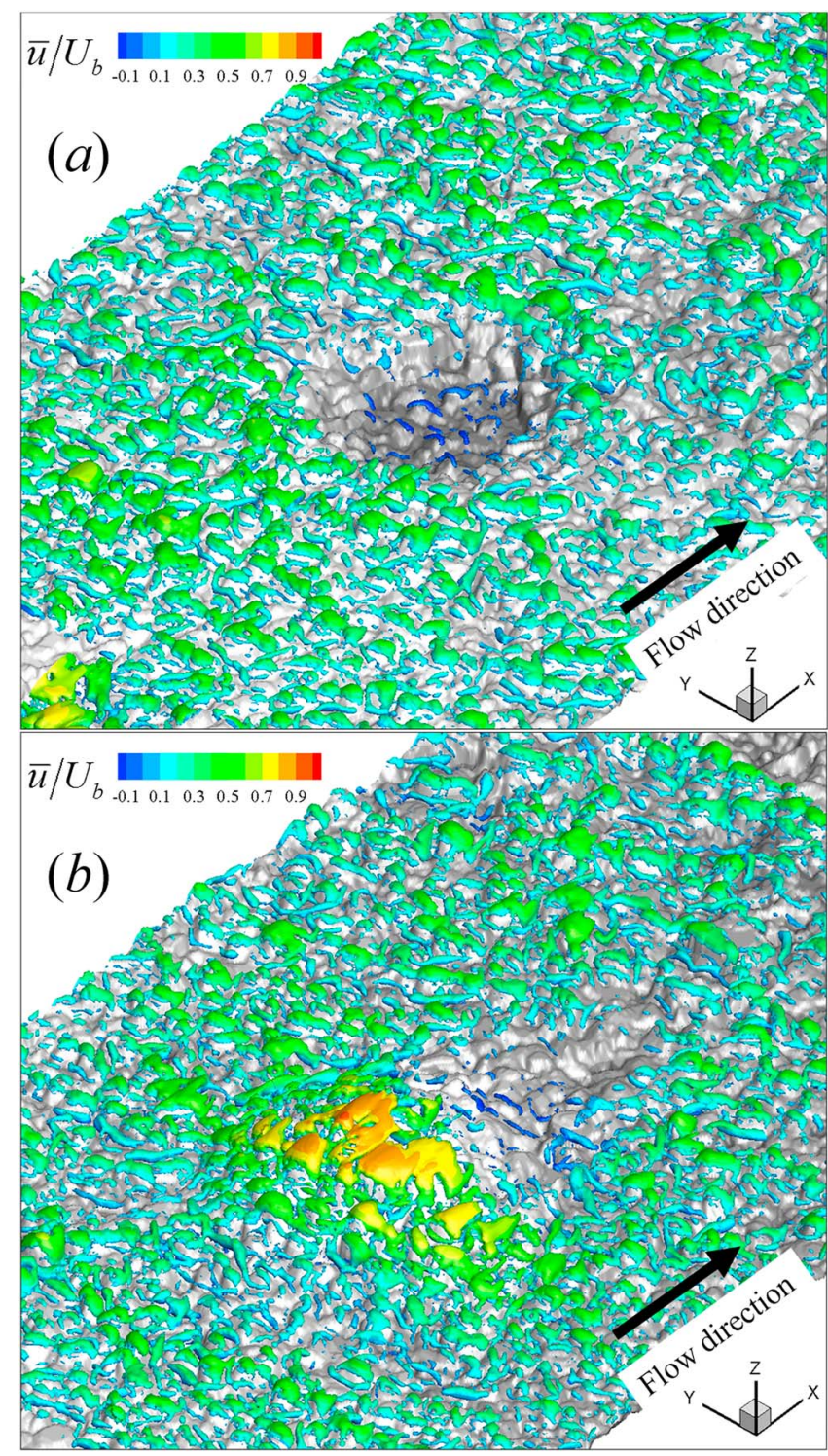

Figure 7. Visualization of arch-shaped vortex tubes over the bed surface using $Q$ iso-surface for (a) the pit and (b) the mound in low velocity. the gravels located around $x=0.1$ and $0.4 \mathrm{~m}$ in Figure $6 \mathrm{c}$. For the mound (Figure 6d), a shear layer exists between the reversed flow region and the overlying flow, which expands downstream about 10 times the mound height.

A zone of maximum turbulent kinetic energy (TKE) is contained within the shear layer for both bedforms (Figures $6 \mathrm{e}$ and $6 \mathrm{f}$ ), and the distributions of TKE are similar to RSS. The mound increases TKE more than the pit, and elevated TKE has greater spatial extent along the bed surface. In addition, the TKE is nearly zero upstream of the pit where reversed flow and low pressure exists. Vorticity is prevalent along the bed surface in both cases, especially where gravel grains protrude (Figures $6 \mathrm{~g}$ and $6 \mathrm{~h}$ ). The high vorticity magnitude in the mean flow is a result of the time averaging of the vorticity associated with the arch-shaped vortex tubes extending over top part of gravels. In Figure $6 \mathrm{~h}$, the maximum vorticity exists over the stoss side of the mound, as the accelerated flow velocity causes more violent vortices. At the leeside of the mound, the vorticity dissipates quickly, within a distance approximately five mound heights in length. The vorticity shows a similar pattern on the upstream edge of the pit as for the leeside of the mound, most likely because of the topographic similarity between these areas. However, the reversed flow inside the pit is more intense and stable than the recirculation zone near the leeside of the mound, with some negative vorticity clearly evident at the bottom of the pit (Figure 6g).

To show the vortex structure more clearly, a $Q$ iso-surface is presented in Figure 7. For both cases, there are prevalent arch-shaped vortices on the bed surface, which are caused by protruding gravels, except for the flow region inside the pit and the region behind the mound, where the absence of vortices is due to the low flow velocity in the reversed flow region. At the stoss side of the mound, the vortices appear to merge and are locally parallel to the edge of the gravel at which they are generated, but they do not extend over the shear layer length behind the mound. The high RSS in the shear layer is caused by instantaneous vortices, which are not stable in time. Therefore, the vortices in the shear layer downstream of the mound disappear in the mean flow field. These vortex tubes are visualized in one of the instantaneous flow fields in Figure 8 for the mound. It shows that most vortex tubes are located within the shear layer, leading to high levels of RSS in the same region. It should be noticed that the $Q$ value is much larger in the instantaneous flow field than that used in the mean flow field.

\subsection{Numerical Results-Flow Exchange Under Low-Flow Conditions}

Figure 9 shows the simulated flow inside the bed and the flow exchange with the overlying surface flow. The pit creates a downwelling area on the downstream face $(x=0.3 \sim 0.36 \mathrm{~m}$; Figure $9 \mathrm{~b})$ and an upwelling zone within the pit itself $(x=0.2 \sim 0.3 \mathrm{~m}$; Figure $9 \mathrm{~b})$, as well as the downstream edge of the pit $(x=0.36 \sim 0.4 \mathrm{~m}$; Figure $9 \mathrm{~b}$ ). The downwelling region in the pit is mainly caused by the flow reattachment, which intrudes into the bed. Part of this intrusion flow reemerges downstream at the rim of the pit, where the accelerating flow leads to a pressure decrease in the fluid. When flow approaches the mound, it is locally deflected, generating a high-pressure area at the upstream face. As shown in Figure 9b, the intruding flow with negative vertical velocity develops as a hemispherical zone below the stoss side of the mound, with resulting porewater flows directed both upstream and downstream. The interstitial flow velocity in this downwelling region is about $0.008 U_{b}$ at the depth of three grain diameters for low-flow conditions. On top of the mound, the flow accelerates due to the reduced cross-sectional area of the flow, which results in decreased pressure, pulling porewater up from deeper sediment layers toward the surface. The velocity of porewater at the depth 


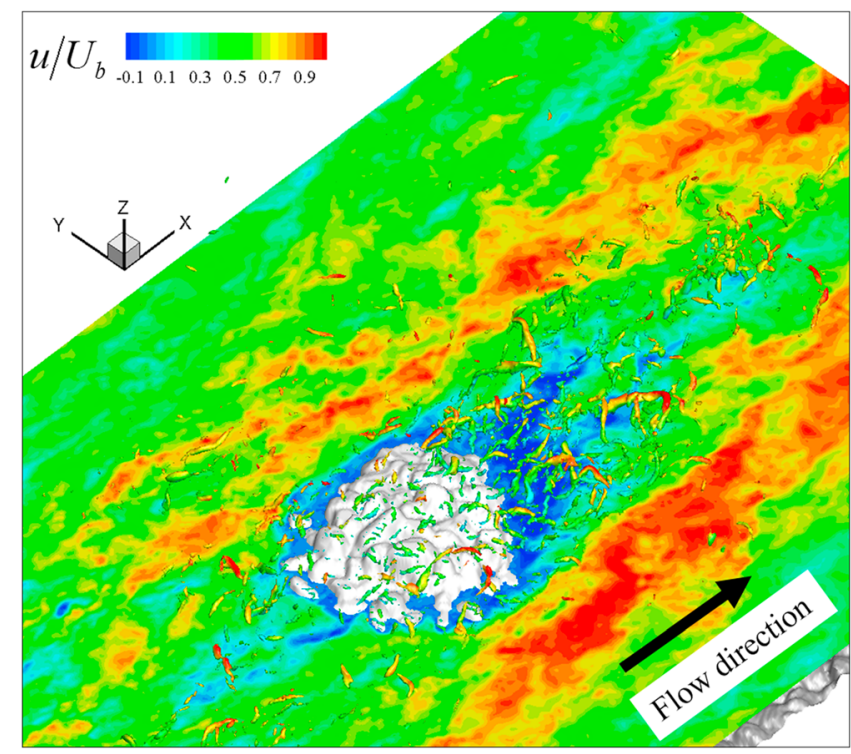

Figure 8. Visualization of instantaneous vortex tubes using $Q$ iso-surface and a paralleled plane colored by instantaneous velocity for the mound in low velocity. The $Q$ iso-surface is colored by the mean streamwise velocity. One horizontal plane colored by instantaneous streamwise velocity is used to blank the vortices closed to the bed surface. of three diameters of the sediment in this region is about $0.012 U_{b}$ in low flow conditions. On the downstream side of the mound, due to the expanding cross-section, decelerating flow causes a second high pressure area and downwelling region. The intruding velocity is about $0.003 U_{b}$ at the depth of three grain diameters under low flows.

Figure 10 shows the distribution of pressure over the pit and the mound. As discussed above, the positive pressure regions correspond to downwelling regions, and negative pressure regions correspond to upwelling regions. Moreover, the magnitude of pressure along the bed surface as well as inside the bed of the mound is greater than that of the pit, illustrating more intense flow exchange and porewater flow caused by the mound. The high coherence of vortex tubes over the pit and the leeside of the mound are illustrated by the instantaneous pressure distribution in Figures $10 \mathrm{~b}$ and $10 \mathrm{~d}$. Inside the vortex tubes, the pressure is reduced to negative values with respect to the background levels, correlating with high local circulation. Most of the vortex tubes lose their coherence around the downstream edge of the pit and before $x=0.5 \mathrm{~m}$ of the mound in Figure 10.

\subsection{Numerical Results-Flow Exchange at Low and High Flows}

The results with low and high flow velocity are presented in this section to show the effects of depth on positions of upwelling and downwelling. As shown in Figure 11, the increase of flow velocity has no obvious effects on the streamwise length of upwelling and downwelling areas while the penetration depth shows some differences. For the pit, from low to high flow velocity, the upwelling depth around $x=0.28 \mathrm{~m}$ and the downwelling depth around $x=0.33 \mathrm{~m}$ increase by 1.5 and 1.3 times, respectively,
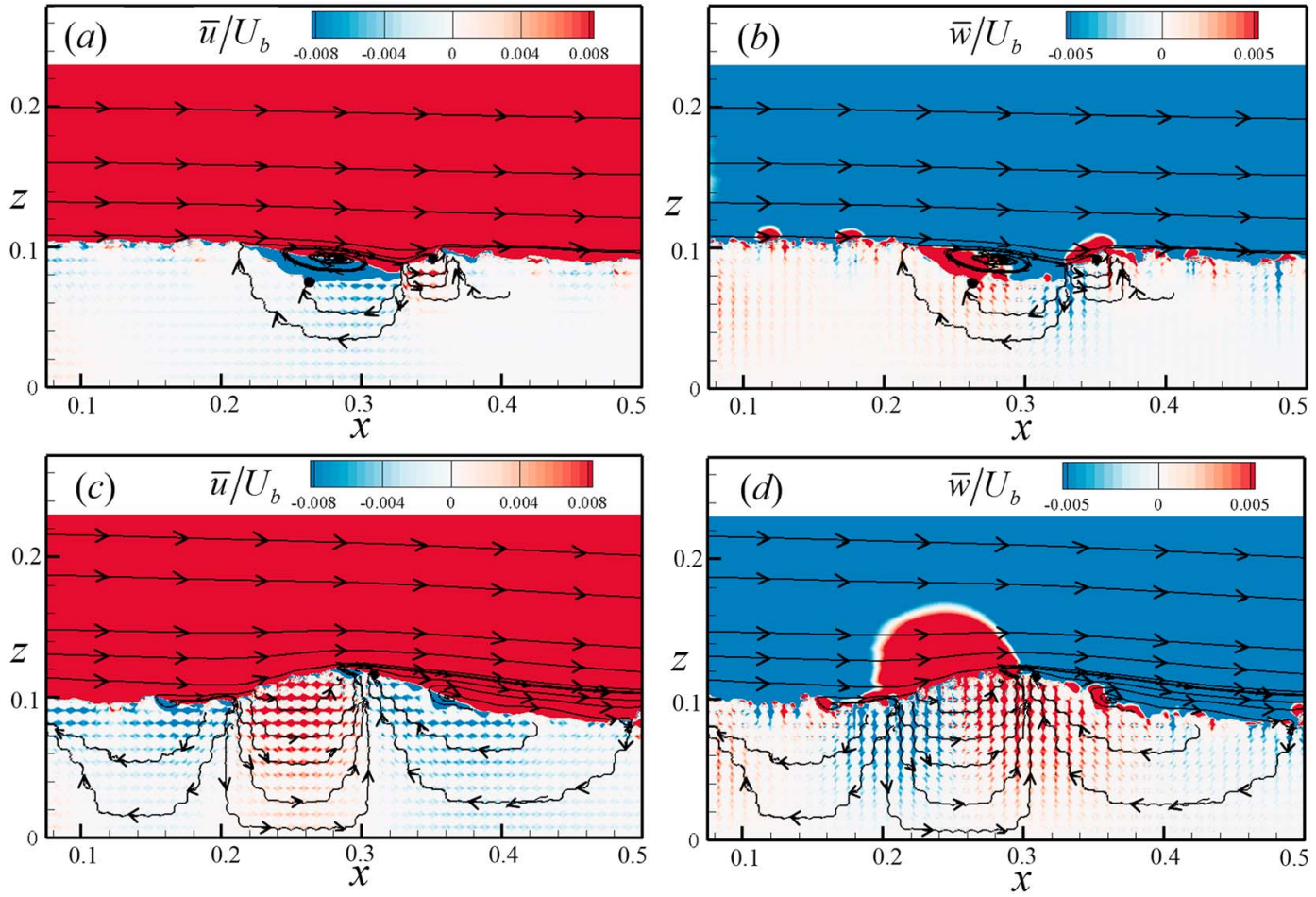

Figure 9. Streamlines and contours of streamwise mean velocity (left panels, a and c) and vertical mean velocity (right panels, b and d) for the pit (top panels, a and b) and the mound (bottom panels, $c$ and d) in low velocity. The $x$ and $z$ are both in meters. Note that the magnitude of velocity inside the bed is low, so the color ramp scale represents a small range of velocities. 

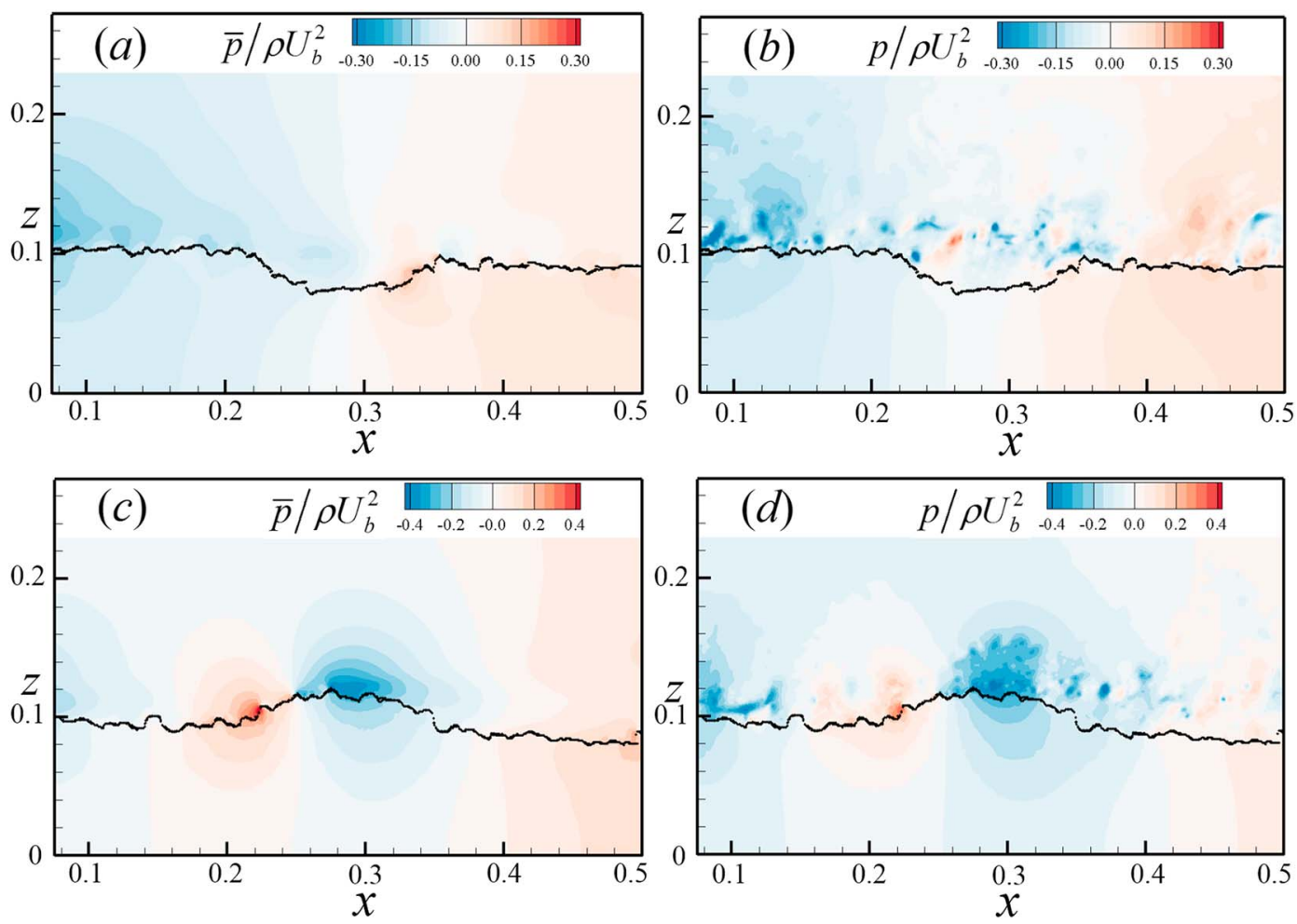

Figure 10. Contours of mean (left panels, a and c) and instantaneous (right panels, b and d) pressure for the pit (top panels, a and b) and the mound (bottom panels, $\mathrm{c}$ and $\mathrm{d}$ ) in low velocity. The $x$ and $z$ are both in meters.

whereas the upwelling depth at the downstream rim (around $x=0.37 \mathrm{dm}$ ) does not change. For the mound, with the increasing flow velocity, the penetration depth around the stoss side and the top of the mound $(x=0.2 \sim 0.33 \mathrm{~m}$ ) increases by 1.3 times. At the leeside of the mound $(x=0.33 \sim 0.38 \mathrm{~m})$, there is an obvious increase of penetration
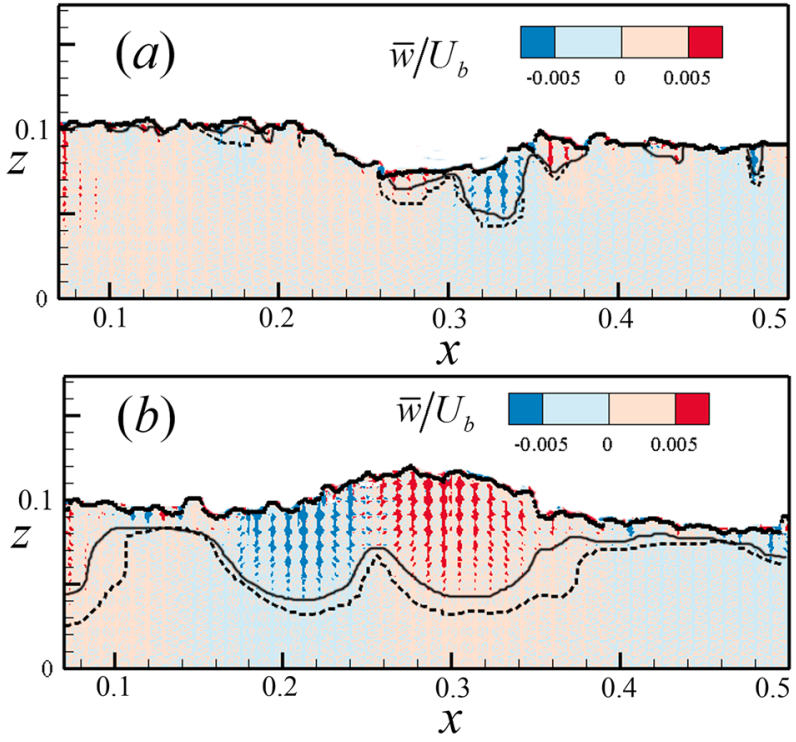

Figure 11. The upwelling and downwelling region for (a) the pit and (b) the mound. The solid and dashed lines show the contour lines of mean vertical velocity with low and high flow velocity, respectively. The contours are the result of low flow velocity. The $x$ and $z$ are both in meters. depth with the ratio of 1.8 .

\subsection{Effect of Flow on Fine-Sediment Entrainment Around the Bed Structures}

In this section we investigate the impact of pit and mound topography on the theoretical entrainment of fine sediment covering the surface, which is a common occurrence in many gravel bed rivers and has implications for the exchange of surface and subsurface water, and the transfer of oxygen and metabolites to and from the bed. The near-bed distribution of RSS and velocity, modeled in section 4.4 , were used to evaluate the regions in which sediment of 0.1-mm $b$-axis diameter (e.g., sand) will be entrained. The proportion of fine sediment in the surface size distribution was set to be $20 \%$. Using the surface-based transport model for mixed-size sediment developed by Wilcock and Crowe (2003), the entrainment threshold of fine sediment $\tau_{\text {cr }}$ was determined. The ratios of mean and instantaneous near-bed RSS to the entrainment threshold of 0.1-mm sediment is shown in Figure 12. For the pit, the fine sediment is stable everywhere and only approaches criticality at the top of protruding gravels. Sediment on the downstream face undergoes higher stresses than on the upstream face, most likely caused by the intense flow exchange in the downwelling region. For the mound, the ratio is relatively high at the downstream edge of the mound, corresponding to the origin of the 



Figure 12. The ratio of mean (a and $c$ ) and instantaneous ( $b$ and d) near-bed shear stress to critical entrainment shear stress of 0.1 -mm sediment in the vicinity of a pit ( $\mathrm{a}$ and $\mathrm{b}$ ) and a mound (c and d) in low velocity. The $x$ and $y$ are both in meters.

shear layer where flow separation occurs. Near the lateral edges of the mound, strong flow acceleration occurs, leading to the amplification of the near-bed stress. The spanwise width of the high shear layer on the one side is about $0.08 \mathrm{~m}(y=0.04 \sim 0.12 \mathrm{~m}$; Figure 12c). At the front of the mound, the shear stress increases due to flow deflection. At the stoss side of the mound, as the flow climbs the mound, the shear stress is negative whereas the downstream side of the mound is associated with low shear stress $(x=$ $0.36 \sim 0.44 \mathrm{~m}$; Figure 12c) because of flow deceleration. Judging by the instantaneous flow field (Figures 12b and 12d), the characteristic regions are similar to those in the mean flow field, but the ratio of near-bed stress to critical entrainment shear stress becomes much greater than that in the mean flow field.

\section{Discussion}

\subsection{Model Performance and Comparison to Other Studies}

We have applied a LES model with bed roughness generated by SfM and sphere-packing permeable bed to predict the near-bed and subsurface flow in the vicinity of pits and mounds. Evaluation between the numerical and experimental results showed good quantitative agreement in the mean flow field with low and high flow velocity. The results of Reynolds normal stress were less similar than the mean flow velocity, but the level of agreement (coefficient of determination was about 0.72) was comparable to other studies that focus on boundary layer flow. For example, the coefficient of determination was 0.42 and 0.43 for TKE in Sinha et al. (2017) and in Ferguson et al. (2003), and the highest values of TKE are underpredicted by about 50\% in Bradbrook et al. (1998). 
The near-bed flow patterns observed are similar to previous studies (Carling et al., 2006; Huettel \& Gust, 1992) giving confidence in the results. Some differences can be ascertained; for example, the size of the recirculation region downstream of the mound is much smaller than that expected over an impermeable and smooth dune, which would normally extend to six bedform heights in the streamwise direction (Best, 2005; Sinha et al., 2017). The smaller size here may be caused by perturbations from the surrounding substrate roughness and the downwelling behind the mound, both rarely incorporated in previous modeling efforts.

It is noted that the flume experiment in the present study did not measure any subsurface flow due to the difficulties of measuring within pore spaces; however, the modeled subsurface flow patterns are similar to the recorded results of Huettel and Gust (1992). For the pit, the upstream and downstream rims correspond to the upwelling region. The high pressure inside the pit causes downwelling at the downstream face of the pit. For the mound, the downwelling region is located in front of the mound, with resulting porewater flows directed upstream and downstream direction. The negative pressure and upwelling are located at the top of the mound, and a second downwelling develops downstream of the mound. However, the diameter of sediment used in their experiments was much finer $(0.3 \mathrm{~mm})$ than the size of gravels used in this study $(8-11$ $\mathrm{mm}$ ). In their flume experiments, the interstitial flow is driven mostly by the surface pressure, and the flow speed just below the surface is about zero $(0.0001 \mathrm{~m} / \mathrm{s})$ compared to the bulk flow velocity (around $0.1 \mathrm{~m} / \mathrm{s}$ ). As the grain diameter becomes larger, the size of pore spaces will increase, increasing flow exchange and the speed of upwelling and downwelling flow, perhaps explaining the comparably faster velocities modeled here. The interstitial flow through salmonid redds in gravel beds has been measured to be between 0.0003 and $0.002 \mathrm{~m} / \mathrm{s}$ in the field (Zimmermann \& Lapointe, 2010) and about $0.001-0.003 \mathrm{~m} / \mathrm{s}$ in previous simulations (Tonina \& Buffington, 2009), similar to the magnitudes recorded in the modeled results. For the pit, a distinction between the findings here in gravels and past work in fine sediment is that the deepest part of the pit is included in the upwelling region (Figure 9) but is a zone of downwelling in fine-sediment beds (Huettel $\&$ Gust, 1992). The differences may be caused by the high bed permeability and intense flow exchange at the downstream side of the pit where flow intrusion occurs, leading to a more concentrated high-pressure zone than the reversed zone. Therefore, the whole reversed zone corresponds to the upwelling region. In addition, the interstitial flow velocity in the upwelling region is about $0.003 U_{b}$ at the depth of three diameters of the sediment below the surface, which is slightly slower than the velocity in the downwelling region.

Previous experiments that conducted simulations of an isolated permeable dune over a permeable bed found that flow through the dune negated the formation of flow separation in the leeside (Blois et al., 2014; Sinha et al., 2017). Although the form of dunes in past work is similar to the mound in those experiments presented here, the results were quite different. There are two main reasons for the discrepancy. First, due to the simple cubic packing method adopted in other simulations, the permeable dune allowed the passage of some flow through it without any blocking, leading to the absence of flow separation. As this straight passage is not realistic, centered cubic packing was adopted in the present study, preventing flow from penetrating straight through bedforms in numerical models. Second, the diameters of spheres that formed the dune and the bed were different in past simulations, resulting in the lack of flow exchange at the interface between two parts. With the uniform composition of the mound and the bed in the present study, the flow exchange prediction is more realistic, given the similarity in conditions between model and experimental conditions. However, it should be noted that assuming constant porosity could neglect the variations of sediment size and overstate the flow rate in the positions where the sediment is finer and less permeable. As sediment composition and grain size in the field are highly nonuniform and spatially variable, we could not directly extrapolate the present quantitative findings to the field. In addition, it is noted that the particles in experiments are more bladed than spherical, which may result in more irregular seepage channels in physical model than in numerical model. Several studies have related the bed tortuosity to bed porosity both theoretically (Berner, 1988) and empirically (Archie, 1942; Boudreau, 1996; Iversen \& Jorgensen, 1993). As the bed porosity in simulations is the same as that in experiments, we may speculate the distinction in the shape of the particles may not have significant influence on the results.

\subsection{Comparison of a Pit to a Mound}

For the near-bed and subsurface flow, the pit had a minimal impact on the surrounding area whereas the influence of the mound extended beyond the physical structure to the surrounding area. Table 3 presents 
Table 3

Near-Bed Flow Variables and Subsurface Flow Variables

\begin{tabular}{|c|c|c|c|c|c|c|}
\hline \multirow{2}{*}{$\begin{array}{l}\text { Flow conditions } \\
\text { Flow variables }\end{array}$} & \multicolumn{3}{|c|}{ Low flow velocity } & \multicolumn{3}{|c|}{ High flow velocity } \\
\hline & Pit & Mound & Ratio & Pit & Mound & Ratio \\
\hline Length of shear layer (cm) & 14 & 20 & 0.7 & 14 & 15 & 0.9 \\
\hline Maximum value of Reynolds shear stress $\left(1 / \mathrm{u}_{*}{ }^{2}\right)$ & 4.8 & 4.1 & 1.17 & 4.9 & 4.3 & 1.14 \\
\hline Maximum value of turbulent kinetic energy $\left(1 / \mathrm{u}_{*}{ }^{2}\right)$ & 10.7 & 12 & 0.89 & 10.5 & 11.7 & 0.9 \\
\hline Length of upwelling/downwelling region (cm) & $10 / 4$ & $12 / 6$ & $0.83 / 0.67$ & $11 / 4$ & $12 / 6$ & $0.91 / 0.67$ \\
\hline Depth of upwelling/downwelling region $(\mathrm{cm})$ & $0.8 / 2.6$ & $6.4 / 4.9$ & $0.13 / 0.53$ & $1.2 / 3.4$ & $8.3 / 6.4$ & $0.14 / 0.53$ \\
\hline
\end{tabular}

Note. Near-bed flow variables: the streamwise length of shear layer (centimeters), the maximum value of Reynolds shear stress and turbulent kinetic energy normalized by $u_{*}{ }^{2}$. Subsurface flow variables: the streamwise length of upwelling and downwelling region (centimeters), the penetration depth of upwelling, and downwelling region (centimeters).

a summary of variables indicating the impact of a pit and mound in low and high flow velocity. It shows that both the streamwise length of the shear layer and the maximum value of TKE were higher over the mound than the pit. While the maximum value of RSS was higher over the pit, that value was located around the reattachment point $(x=0.33 \mathrm{~m}$ in Figure $7 \mathrm{c})$. Two main upwelling/downwelling regions inside the pit ( $x=0.26$ and $0.34 \mathrm{~m}$ in Figure $10 \mathrm{~b})$ and over the mound $(x=0.2$ and $0.3 \mathrm{~m}$ in Figure 10d) were considered when calculating the penetration depth. The results showed that the streamwise length of the upwelling or downwelling region was limited around the pit, that is, $x=0.2 \sim 0.4 \mathrm{~m}$, while it expanded to $x=0.06 \sim 0.5 \mathrm{~m}$ for the mound. Moreover, the ratio of penetration depth was much higher than the ratio of streamwise length between two kinds of bed structures, especially for the upwelling region, illustrating the mound contributed most to the penetration depth. At the sediment-water interface, the intruding velocity is higher than reemerging velocity over the pit, and the relative magnitude changes over the mound.

The distribution of critical Shields values was related to bed topography, with high relative elevation leading to a higher entrainment potential. However, it should be noted that grain position will also be important. On the mound, the highest shear stresses occur on the downstream top edge, where friction angles are also low, making these grains vulnerable to entrainment. In contrast, the highest stresses in the pit occur on the downstream face where friction angles are high and grains will be relatively hard to move.

\subsection{Potential Significance of Biogenic Bedforms to Aquatic Animals}

Aquatic animals in rivers actively construct pits and mounds to provide shelter to avoid predators (Statzner et al., 2000) and to situate eggs (Groot \& Margolis, 1991; Quinn, 2018). Biogenic bedforms may also have other benefits due to their flow effects. For example, the recirculation region in the leeside of a mound or inside of the pit is likely to act as a collector for suspended material and thus to increase the availability of food particles in these areas. A similar effect is known to facilitate the filter or deposit feeding strategy of many animals that use their body form to generate vortices to encourage food particle deposition (Carey, 1983; Friedrichs \& Graf, 2009). As the near-bed velocity inside the pit and behind the mound was relatively low, animals located there will experience minimal flow stresses and minimize potential dislocation. This could be significant to animals such as crayfish, which are large and not streamlined, leaving them vulnerable to entrainment. Being able to posture in a pit, reducing their exposure to the flow, could be highly beneficial (Maude \& Williams, 1983).

At the downstream end of the pit, violent downwelling occurs, causing flow intrusion into the bed. At the top of the mound, the accelerating flow and low pressure cause upwelling from the bed. The corresponding flux may be biologically important, as some fish redds are combinations of pit and mounds (Crisp \& Carling, 1989; Tonina \& Buffington, 2009). Salmonid redds oxygenate buried embryos, removing waste products, and enhance embryo survival to emergence (Coble, 1961; Greig et al., 2007; Tonina \& Buffington, 2009). A shear layer is found above the pit as well as around the downwelling region due to intense momentum exchange. The analysis of 0.1-mm sediment shows that areas of high shear stresses are likely associated with entrainment of fines and areas of low stress to fine sediment deposition. If 
entrainment of fines leads to a coarser matrix in downwelling regions, finer material may be entrained and infiltrate into the subsurface sediment pores, causing the subsurface material to become finer (Beschta \& Jackson, 1979; Casas-Mulet et al., 2017; Franssen et al., 2014; Lisle, 1989; Meyer et al., 2005; Mooneyham \& Strom, 2018; Papanicolaou et al., 2011; Wooster et al., 2008). For example, the shear stress around the downstream part of the pit is relatively high, and this corresponds to the downwelling region. Thus, we can speculate that if finer sediment comes from the upstream, the permeability of the bed in that region will decrease, and the top layer of the bed may be clogged due to the intrusion of the finer sediment. This may suppress the mass transfer and flow exchange to the deeper bed, causing problems such as increased fish-egg mortality rates. In contrast, if deposition corresponds to an upwelling region, such as upstream of the pit, the upwelling flow may flush the fine sediment or restrict its deposition.

In the present study, we focused on the basic unit of the chosen biological bedforms (i.e., the pit and the mound). Due to the complexity of actual biogenic prototypes, the inferences drawn here are primarily about constructed bedforms. In natural streambed settings the excavation of a pit often forms an adjacent mound. Together these two associated forms may uniquely influence flow patterns and exchange processes. There are many different species that excavate pits into streambed sediments, and multiple factors (e.g., mode of excavation, the size of the organism, and the characteristics of the streambed and flow field) interact to create pits and/or mounds of variable size and form. The positioning and height of the mound relative to the pit will be critical to the flow field and are variable. For example, crayfish tend to distribute excavated material widely around the pit, potentially giving them a better view of predators and competitors by limiting the mound height (Johnson et al., 2010). In contrast, in salmon redds the large grains settle in the pit, and the finer sediment is deposited to a downstream mound called the tailspill (Buxton et al., 2015; Tonina \& Buffington, 2009). In addition, the variations in grain size and hydraulic conductivity across redds will cause different subsurface flow patterns in comparison to bedforms with well-sorted gravels. Changing the diameter and shape of the grains used to form the permeable beds in modeled simulations may achieve the goal of realistically simulating flow over and through salmonid redds but would be more computationally challenging.

\section{Conclusions}

The near-bed turbulence and hyporheic exchange are important to sediment stability, solute transfer across the sediment-water interface and survival of benthic organisms. The surface and subsurface flow in rivers can be influenced by grain roughness, bedforms, and bed permeability. All these three factors were included in the present unified water-sediment three-dimensional model. The LES model with the combination of substrate roughness generated by SfM and subsurface sphere-packing beds performed well. Evaluation using flume experiments indicated that numerical results successfully approximated measurements. Experiments and modeling demonstrated that pits and mounds distorted the surrounding flow, increasing heterogeneity in the flow environment. The results are supported by another work that indicates that mound-like structures act as a bluff body, with flow accelerating over and around them and recirculation downstream. Flow skims over the pit, with low flow and recirculation in the pit itself. The numerical results extend this knowledge by also showing that these topographic features may promote exchange processes with subsurface flow, with pressure differences over the objects driving vertical porewater flows. For the pit, the length of the downwelling region is smaller than the upwelling region, and the flow velocity is higher in the region of downwelling region. In contrast, a zone of downwelling exists upstream of the mound as flow is forced into the structure, and upwelling occurs over the top of the mound. The size of the separation zone is limited on the leeside of the mound because mounds constructed by animals tend to be more symmetrical than dunes. With an increase in velocity, the upwelling depth on the leeside of the mound increases dramatically while the streamwise length of upwelling and downwelling region shows little change. The numerical results are helpful in extending our knowledge of the potential role of living organisms in affecting sediment entrainment, the near bed hydraulic environment, and flow exchange through modifications in bed topography. Further research could include multiple pits and mounds or typical redd structures to see the potential impacts on these processes. Better understanding of these processes, and the interaction between life, bed structure, and topography, and near-bed hydraulics would help develop more complete models of riverbed entrainment, function, and metabolism. 


\section{Acknowledgments}

This investigation was supported by the 111 Project (B18031) and the National Natural Science Foundation of China (91647210). Thanks for the financial support provided by the China Scholarship Council (CSC) (201706210236). Numerical and experimental data presented herein can be downloaded from the Zenodo website (https://zenodo.org/record/2633605\#. XKwwYrEYx5s, doi: 10.5281/ zenodo.2633605)

\section{References}

Abelson, A., \& Denny, M. (1997). Settlement of marine organisms in flow. Annual Review of Ecology and Systematics, 28, 317-339. https:// doi.org/10.1146/annurev.ecolsys.28.1.317

Archie, G. E. (1942). The electrical resistivity log as an aid in determining some reservoir characteristics. Transactions of the AIME, 146(01), 54-62. https://doi.org/10.2118/942054-G

Bardini, L., Boano, F., Cardenas, M. B., Revelli, R., \& Ridolfi, L. (2012). Nutrient cycling in bedform induced hyporheic zones. Geochimica ET Cosmochimica Acta, 84, 47-61. https://doi.org/10.1016/j.gca.2012.01.025

Berner, R. A. (1988). Citation classic-Early diagenesis-A theoretical approach. Current Contents/Agriculture Biology \& Environmental Sciences, 44, 18-18.

Beschta, R. L., \& Jackson, W. L. (1979). The Intrusion of fine sediments into a stable gravel bed. Journal of the Fisheries Research Board of Canada, 36(2), 204-210. https://doi.org/10.1139/f79-030

Best, J. (2005). The fluid dynamics of river dunes: A review and some future research directions. Journal of Geophysical Research, 110, F04S02. https://doi.org/10.1029/2004JF000218

Blois, G., Best, J. L., Smith, G. H. S., \& Hardy, R. J. (2014). Effect of bed permeability and hyporheic flow on turbulent flow over bed forms Geophysical Research Letters, 41, 6435-6442. https://doi.org/10.1002/2014GL060906

Blois, G., Smith, G. H. S., Best, J. L., Hardy, R. J., \& Lead, J. R. (2012). Quantifying the dynamics of flow within a permeable bed using time-resolved endoscopic particle imaging velocimetry (EPIV). Experiments in Fluids, 53(1), 51-76. https://doi.org/10.1007/s00348-011$1198-8$

Bomminayuni, S., \& Stoesser, T. (2011). Turbulence statistics in an open-channel flow over a rough bed. Journal of Hydraulic EngineeringASCE, 137(11), 1347-1358. https://doi.org/10.1061/(ASCE)HY.1943-7900.0000454

Boudreau, B. P. (1996). The diffusive tortuosity of fine-grained unlithified sediments. Geochimica Et Cosmochimica Acta, 60(16), 3139-3142. https://doi.org/10.1016/0016-7037(96)00158-5

Bradbrook, K. F., Biron, P. M., Lane, S. N., Richards, K. S., \& Roy, A. G. (1998). Investigation of controls on secondary circulation in a simple confluence geometry using a three-dimensional numerical model. Hydrological Processes, 12(8), 1371-1396. https://doi.org/ 10.1002/(Sici)1099-1085(19980630)12:8<1371::Aid-Hyp620>3.0.Co;2-C

Butler, D. R. (2002). The environmental impact of crayfish biopedoturbation on a floodplain: Roanoke River, North Carolina Coastal Plain, U.S.A. Landform Analysis, 3, 35-40.

Butler, J. B., Lane, S. N., Chandler, J. H., \& Porfiri, E. (2002). Through-water close range digital photogrammetry in flume and field environments. The Photogrammetric Record, 17(99), 419-439. https://doi.org/10.1111/0031-868x.00196

Buxton, T. H., Buffington, J. M., Tonina, D., Fremier, A. K., \& Yager, E. M. (2015). Modeling the influence of salmon spawning on hyporheic exchange of marine-derived nutrients in gravel stream beds. Canadian Journal of Fisheries and Aquatic Sciences, 72(8), 1146-1158. https://doi.org/10.1139/cjfas-2014-0413

Cardenas, M. B., Ford, A. E., Kaufman, M. H., Kessler, A. J., \& Cook, P. L. M. (2017). Hyporheic flow and dissolved oxygen distribution in fish nests: the effects of open channel velocity, permeability patterns, and groundwater upwelling: Hyporheic flow and DO inside fish nests. Journal of Geophysical Research: Biogeosciences, 121, 3113-3130. https://doi.org/10.1002/2016JG003381

Carey, D. A. (1983). Particle resuspension in the benthic boundary-layer induced by flow around polychaete tubes. Canadian Journal of Fisheries and Aquatic Sciences, 40, 301-308.

Carling, P. A., Whitcombe, L., Benson, I. A., Hankin, B. G., \& Radecki-Pawlik, A. M. (2006). A new method to determine interstitial flow patterns in flume studies of sub-aqueous gravel bedforms such as fish nests. River Research and Applications, 22(6), 691-701. https://doi. org/10.1002/rra.930

Casas-Mulet, R., Alfredsen, K. T., McCluskey, A. H., \& Stewardson, M. J. (2017). Key hydraulic drivers and patterns of fine sediment accumulation in gravel streambeds: A conceptual framework illustrated with a case study from the Kiewa River, Australia. Geomorphology, 299, 152-164. https://doi.org/10.1016/j.geomoiph.2017.08.032

Cevheri, M., McSherry, R., \& Stoesser, T. (2016). A local mesh refinement approach for large-eddy simulations of turbulent flows. International Journal for Numerical Methods in Fluids, 82(5), 261-285. https://doi.org/10.1002/fld.4217

Claret, C., Marmonier, P., Boissier, J. M., Fontvieille, D., \& Blanc, P. (2010). Nutrient transfer between parafluvial interstitial water and river water: Influence of gravel bar heterogeneity. Freshwater Biology, 37(3), 657-670.

Coble, R. L. (1961). Sintering crystalline solids. 2. Experimental test of duffusion models in powder compacts. Journal of Applied Physics, 32(5), 793-790. https://doi.org/10.1063/1.1736108

Constantinescu, G., Miyawaki, S., \& Liao, Q. (2013). Flow and turbulence structure past a cluster of freshwater mussels. Journal of Hydraulic Engineering-ASCE, 139(4), 347-358. https://doi.org/10.1061/(Asce)Hy.1943-7900.0000692

Cooper, J. R., Ockleford, A., Rice, S. P., \& Powell, D. M. (2018). Does the permeability of gravel river beds affect near-bed hydrodynamics? Earth Surface Processes and Landforms, 43(5), 943-955. https://doi.org/10.1002/esp.4260

Crisp, D. T., \& Carling, P. A. (1989). Observations on siting, dimensions and structure of salmonid redds. Journal of Fish Biology, 34(1), 119-134. https://doi.org/10.1111/j.1095-8649.1989.tb02962.x

Dinehart, R. L. (1992). Gravel-bed deposition and erosion by bedform migration observed ultrasonically during storm flow, North Fork Toutle River, Washington. Journal of Hydrology, 136(1-4), 51-71. https://doi.org/10.1016/0022-1694(92)90004-F

Dybbs, A., \& Edwards, R. V. (1984). A new look at porous media fluid mechanics-Darcy to turbulent, (pp. 199-256). Netherlands: Springer.

Elliott, A. H., \& Brooks, N. H. (1997). Transfer of nonsorbing solutes to a streambed with bed forms: Laboratory experiments. Water Resources Research, 33(1), 137-151. https://doi.org/10.1029/96WR02783

Fang, H. W., Bai, J., He, G. J., \& Zhao, H. M. (2014). Calculations of nonsubmerged groin flow in a shallow open channel by large-eddy simulation. Journal of Engineering Mechanics, 140(5). https://doi.org/10.1061/(asce)em.1943-7889.0000711

Fang, H. W., Han, X., He, G. J., \& Dey, S. (2018). Influence of permeable beds on hydraulically macro-rough flow. Journal of Fluid Mechanics, 847, 552-590. https://doi.org/10.1017/jfm.2018.314

Ferguson, R. I., Parsons, D. R., Lane, S. N., \& Hardy, R. J. (2003). Flow in meander bends with recirculation at the inner bank. Water Resources Research, 39(11), 1322. https://doi.org/10.1029/2003WR001965

Franssen, J., Lapointe, M., \& Magnan, P. (2014). Geomorphic controls on fine sediment reinfiltration into salmonid spawning gravels and the implications for spawning habitat rehabilitation. Geomorphology, 211, 11-21. https://doi.org/10.1016/j. geomorph.2013.12.019

Friedrichs, M., \& Graf, G. (2009). Characteristic flow patterns generated by macrozoobenthic structures. Journal of Marine Systems, 75(3-4), 348-359. https://doi.org/10.1016/j.jmarsys.2007.01.015 
Graf, W. H., \& Istiarto, I. (2002). Flow pattern in the scour hole around a cylinder. Journal of Hydraulic Research, 40(1), 13-20. https://doi. org/10.1080/00221680209499869

Greig, S. M., Sear, D. A., \& Carling, P. A. (2007). A review of factors influencing the availability of dissolved oxygen to incubating salmonid embryos. Hydrological Processes, 21(3), 323-334. https://doi.org/10.1002/hyp.6188

Groot, C., \& Margolis, L. (1991). Pacific salmon life histories, (pp. 347-348). Vancouver: UBC Press.

Han, X., Fang, H. W., He, G. J., \& Reible, D. (2018). Effects of roughness and permeability on solute transfer at the sediment water interface. Water Research, 129, 39-50. https://doi.org/10.1016/j.watres.2017.10.049

Harnanan, S., Soontiens, N., \& Stastna, M. (2015). Internal wave boundary layer interaction: A novel instability over broad topography. Physics of Fluids, 27(1). https://doi.org/10.1063/1.4906299

Hassan, M. A., Gottesfeld, A. S., Montgomery, D. R., Tunnicliffe, J. F., Clarke, G. K. C., Wynn, G., et al. (2008). Salmon-driven bed load transport and bed morphology in mountain streams. Geophysical Research Letters, 35, L04405. https://doi.org/10.1029/2007GL032997

Hassan, M. A., \& Reid, I. (1990). The influence of microform bed roughness elements on flow and sediment transport in gravel bed rivers. Earth Surface Processes and Landforms, 15(8), 739-750. https://doi.org/10.1002/esp.3290150807

Hein, F. J., \& Walker, R. G. (1977). Bar evolution and development of stratification in the gravelly, braid. Canadian Journal of Earth Sciences, 14(4), 562-570. https://doi.org/10.1139/e77-058

Heritage, G. L., \& Milan, D. J. (2009). Terrestrial laser scanning of grain roughness in a gravel-bed river. Geomorphology, 113(1-2), 4-11. https://doi.org/10.1016/j.geomorph.2009.03.021

Herrington, S. J., \& Popp, K. J. (2004). Observations on the reproductive behavior of nonindigenous rough shiner, Notropis baileyi, in the Chattahoochee River system. Southeastern Naturalist, 3(2), 267-276. https://doi.org/10.1656/1528-7092(2004)003[0267: Ootrbo]2.0.Co;2

Higashino, M. (2013). Quantifying a significance of sediment particle size to hyporheic sedimentary oxygen demand with a permeable stream bed. Environmental Fluid Mechanics, 13(3), 227-241. https://doi.org/10.1007/s10652-012-9262-3

Higashino, M., Clark, J. J., \& Stefan, H. G. (2009). Pore water flow due to near-bed turbulence and associated solute transfer in a stream or lake sediment bed. Water Resources Research, 45, W12414. https://doi.org/10.1029/2008WR007374

Hilldale, R. C. (2007), Identifying stream habitat features with a two-dimensional hydraulic model, 33 pp., Technical Series TSYSS-12, Bureau of Reclamation Technical Service Center, Denver, CO.

Hogg, R. S., Coghlan, S. M., Zydlewski, J., \& Simon, K. S. (2014). Anadromous sea lampreys (Petromyzon marinus) are ecosystem engineers in a spawning tributary. Freshwater Biology, 59(6), 1294-1307. https://doi.org/10.1111/fwb.12349

Horton, N. A., \& Pokrajac, D. (2009). Onset of turbulence in a regular porous medium: an experimental study. Physics of Fluids, 21(4). https://doi.org/10.1063/1.3091944

Huettel, M., \& Gust, G. (1992). Impact of bioroughness on interfacial solute exchange in permeable sediments. Marine Ecology Progress Series, 89(2-3), 253-267. https://doi.org/10.3354/meps089253

Hunt, J. C. R., Wray, A., and Moin, P. (1988). Eddies, stream, and convergence zones in turbulent flows, Process of the 1998 Summer Program (Center for Turbulence Research, Stanford, CA), 193-202.

Inoue, T., \& Nakamura, Y. (2011). Effects of hydrodynamic conditions on DO transfer at a rough sediment surface. Journal of Environmental Engineering, 137(1), 28-37. https://doi.org/10.1061/(asce)ee.1943-7870.0000293

Iversen, N., \& Jorgensen, B. B. (1993). Diffusion-coefficients of sulfate and methane in marine-sediments-Influence of porosity. Geochimica Et Cosmochimica Acta, 57(3), 571-578. https://doi.org/10.1016/0016-7037(93)90368-7

Johnson, M. F., Rice, S. P., \& Reid, I. (2010). Topographic disturbance of subaqueous gravel substrates by signal crayfish (Pacifastacus leniusculus). Geomorphology, 123(3-4), 269-278. https://doi.org/10.1016/j.geomorph.2010.07.018

Johnson, M. F., Rice, S. P., \& Reid, I. (2011). Increase in coarse sediment transport associated with disturbance of gravel river beds by signal crayfish (Pacifastacus leniusculus). Earth Surface Processes and Landforms, 36(12), 1680-1692. https://doi.org/10.1002/esp.2192

Johnson, M. F., Rice, S. P., \& Richardson, J. (2014). Animal perception in gravel-bed rivers: Scales of sensing and environmental controls on sensory information. Canadian Journal of Fisheries and Aquatic Sciences, 71(6), 945-957. https://doi.org/10.1139/cjfas-2013-0474

Kampanis, N. A., \& Ekaterinaris, J. A. (2006). A staggered grid, high-order accurate method for the incompressible Navier-Stokes equations. Journal of Computational Physics, 215(2), 589-613. https://doi.org/10.1016/j.jcp.2005.11.014

Kara, M. C., Stoesser, T., \& McSherry, R. (2015). Calculation of fluid-structure interaction: Methods, refinements, applications. Proceedings of the Institution of Civil Engineers-Engineering and Computational Mechanics, 168(2), 59-78. https://doi.org/10.1680/eacm.15.00010

Keshavarzi, A., Ball, J., \& Nabavi, H. (2012). Frequency pattern of turbulent flow and sediment entrainment over ripples using image processing. Hydrology and Earth System Sciences, 16(1), 147-156. https://doi.org/10.5194/hess-16-147-2012

Kleinhans, M. G. (2004). Sorting in grain flows at the lee side of dunes. Earth-Science Reviews, 65(1-2), 75-102. https://doi.org/10.1016/ S0012-8252(03)00081-3

Kondolf, G. M. (2000). Assessing salmonid spawning gravel quality. Transactions of the American fisheries Society, 129(1), 262-281. https:// doi.org/10.1577/1548-8659(2000)129<0262:Assgq > 2.0.Co;2

Krumbein, W. C. (1941). Measurement and geological significance of shape and roundness of sedimentary particles. Journal of Sedimentary Research, 11(2), 64-72. https://doi.org/10.1306/d42690f3-2b26-11d7-8648000102c1865d

Lacey, R. W. J., \& Roy, A. G. (2007). A comparative study of the turbulent flow field with and without a pebble cluster in a gravel bed river. Water Resources Research, 43, W05502. https://doi.org/10.1029/2006WR005027

Lachner, E. A. (1952). Studies of the biology of the cyprinid fishes of the chub genus Nocomis of Northeastern United States. The American Midland Naturalist, 48(2), 433. https://doi.org/10.2307/2422260

Lisle, T. E. (1989). Sediment transport and resulting deposition in spawning gravels, North Coastal California. Water Resources Research, 25(6), 1303-1319. https://doi.org/10.1029/WR025i006p01303

Manes, C., Pokrajac, D., McEwan, I., \& Nikora, V. (2009). Turbulence structure of open channel flows over permeable and impermeable beds: A comparative study. Physics of Fluids, 21(12). https://doi.org/10.1063/1.3276292

Marion, A., Bellinello, M., Guymer, I., \& Packman, A. (2002). Effect of bed form geometry on the penetration of nonreactive solutes into a streambed. Water Resources Research, 38(10), 1209. https://doi.org/10.1029/2001WR000264

Maude, S. H., \& Williams, D. D. (1983). Behavior of crayfish in water currents-hydrodynamics of 8 species with reference to their distribution patterns in southern Ontario. Canadian Journal of Fisheries and Aquatic Sciences, 40(1), 68-77. https://doi.org/10.1139/f83-010

Meyer, C. B., Sparkman, M. D., \& Klatte, B. A. (2005). Sand seals in coho salmon redds: Do they improve egg survival? North American Journal of Fisheries Management, 25(1), 105-121. https://doi.org/10.1577/M03-217.1

Meysman, F. J. R., Galaktionov, E. S., Gribsholt, B., \& Middelburg, J. J. (2006). Bioirrigation in permeable sediments: Advective pore-water transport induced by burrow ventilation. Limnology and Oceanography, 51(1), 142-156. https://doi.org/10.4319/lo.2006.51.1.0142 
Mooneyham, C., \& Strom, K. (2018). Deposition of suspended clay to open and sand-filled framework gravel beds in a laboratory flume. Water Resources Research, 54, 323-344. https://doi.org/10.1002/2017WR020748

Murray, J. M. H., Meadows, A., \& Meadows, P. S. (2002). Biogeomorphological implications of microscale interactions between sediment geotechnics and marine benthos: A review. Geomorphology, 47(1), 15-30. https://doi.org/10.1016/S0169-555x(02)00138-1

Muzzammil, M., \& Gangadhariah, T. (2003). The mean characteristics of horseshoe vortex at a cylindrical pier. Journal of Hydraulic Research, 41(3), 285-297. https://doi.org/10.1080/00221680309499973

Nakamura, Y., \& Stefan, H. G. (1994). Effect of flow velocity on sediment oxygen demand: Theory. Journal of Environmental EngineeringASCE, 120(5), 996-1016. https://doi.org/10.1061/(asce)0733-9372(1994)120:5(996)

Nicoud, F., \& Ducros, F. (1999). Subgrid-scale stress modelling based on the square of the velocity gradient tensor. Flow Turbulence and Combustion, 62(3), 183-200. https://doi.org/10.1023/A:1009995426001

Nikora, V. I., \& Rowinski, P. M. (2008). Rough-bed flows in geophysical, environmental, and engineering systems: Double-averaging approach and its applications. Acta Geophysica, 56(3), 529-533. https://doi.org/10.2478/s11600-008-0037-7

Orvain, F. (2005). A model of sediment transport under the influence of surface bioturbation: Generalisation to the facultative suspensionfeeder Scrobicularia plana. Marine Ecology Progress Series, 286, 43-56. https://doi.org/10.3354/meps286043

Papanicolaou, A. N., Dermisis, D. C., \& Elhakeem, M. (2011). Investigating the role of clasts on the movement of sand in gravel bed rivers. Journal of Hydraulic Engineering-ASCE, 137(9), 871-883. https://doi.org/10.1061/(Asce)Hy.1943-7900.0000381

Peine, F., Friedrichs, M., \& Graf, G. (2009). Potential influence of tubicolous worms on the bottom roughness length z(0) in the southwestern Baltic Sea. Journal of Experimental Marine Biology and Ecology, 374(1), 1-11. https://doi.org/10.1016/j.jembe.2009.03.016

Peskin, C. S. (1972). Flow patterns around heart valves-numerical method. Journal of Computational Physics, 10(2), 252-271. https://doi. org/10.1016/0021-9991(72)90065-4

Pledger, A. G., Rice, S. P., \& Millett, J. (2017). Foraging fish as zoogeomorphic agents: an assessment of fish impacts at patch, barform, and reach scales. Journal of Geophysical Research: Earth Surface, 122, 2105-2123. https://doi.org/10.1002/2017JF004362

Qian, Q., Clark, J. J., Voller, V. R., \& Stefan, H. G. (2009). Depth-dependent dispersion coefficient for modeling of vertical solute exchange in a lake bed under surface waves. Journal of Hydraulic Engineering-ASCE, 135(3), 187-197. https://doi.org/10.1061/(asce)07339429(2009)135:3(187)

Quinn, T. P. (2018). Behavior and ecology of pacific salmon and trout. Washington: University of Washington Press.

Rice, S. P., Buffin-Bélanger, T., \& Reid, I. (2014). Sensitivity of interfacial hydraulics to the microtopographic roughness of water-lain gravels. Earth Surface Processes and Landforms, 39(2), 184-199. https://doi.org/10.1002/esp.3438

Rice, S. P., M. F. Johnson, \& I. Reid (2012), Animals and the geomorphology of gravel-bed rivers.

Roy, H., Huttel, M., \& Jorgensen, B. B. (2002). The role of small-scale sediment topography for oxygen flux across the diffusive boundary layer. Limnology and Oceanography, 47(3), 837-847. https://doi.org/10.4319/10.2002.47.3.0837

Sabaj, M. H., Maurakis, E. G., \& Woolcott, W. S. (2000). Spawning behaviors in the bluehead chub, Nocomis leptocephalus, River Chub, N micropogon and central stoneroller, Campostoma anomalum. The American Midland Naturalist, 144(1), 187-201. https://doi.org/ 10.1674/0003-0031(2000)144[0187:Sbitbc]2.0.Co;2

Sarkar, S., Papanicolaou, A. N. T., \& Dey, S. (2016). Turbulence in a gravel-bed stream with an array of large gravel obstacles. Journal of Hydraulic Engineering, 142(11), 1-11. https://doi.org/10.1061/(asce)hy.1943-7900.0001191

Schlichting, H. (1980). Citation classic-boundary-layer theory. Current Contents-Engineering Technology and Applied Sciences, 23, 12-12.

Sinha, S., Hardy, R. J., Blois, G., Best, J. L., \& Smith, G. H. S. (2017). A numerical investigation into the importance of bed permeability on determining flow structures over river dunes. Water Resources Research, 53, 3067-3086. https://doi.org/10.1002/2016WR019662

Sneed, E. D., \& Folk, R. L. (1958). Pebbles in the lower Colorado River, Texas a study in particle morphogenesis. Journal of Geology, 66(2), 114-150. https://doi.org/10.1086/626490

Statzner, B., Fievet, E., Champagne, J. Y., Morel, R., \& Herouin, E. (2000). Crayfish as geomorphic agents and ecosystem engineers: Biological behavior affects sand and gravel erosion in experimental streams. Limnology and Oceanography, 45(5), 1030-1040. https://doi. org/10.4319/lo.2000.45.5.1030

Stoesser, T., \& Nikora, V. I. (2008). Flow structure over square bars at intermediate submergence: Large eddy simulation study of bar spacing effect. ACTA GEOPHYSICA, 56(3), 876-893. https://doi.org/10.2478/s11600-008-0030-1

Szeliski, R. (2011), Computer vision algorithms and applications introduction, Texts Comput Sci, 1-28, doi: Book_Doi https://doi.org/ 10.1007/978-1-84882-935-0.

Tang, C., Zhu, X. Z., Chen, J. J., Wang, P. C., Liu, X. W., \& Tian, J. (2018). Robust graph regularized unsupervised feature selection. Expert Systems with Applications, 96, 64-76. https://doi.org/10.1016/j.eswa.2017.11.053

Tonina, D., \& Buffington, J. M. (2007). Hyporheic exchange in gravel bed rivers with pool-riffle morphology: Laboratory experiments and three-dimensional modeling. Water Resources Research, 43, W014211. https://doi.org/10.1029/2005WR004328

Tonina, D., \& Buffington, J. M. (2009). A three-dimensional model for analyzing the effects of salmon redds on hyporheic exchange and egg pocket habitat. Canadian Journal of Fisheries and Aquatic Sciences, 66(12), 2157-2173. https://doi.org/10.1139/F09-146

Tubino, M., Repetto, R., \& Zolezzi, G. (1999). Free bars in rivers. Journal of Hydraulic Research, 37(6), 759-775. https://doi.org/10.1080/ 00221689909498510

Vanoni, V. A. (1975), Sedimentation engineering, American Society of Civil Enginerring, Task Committee for the Preparation of the Manual on Sedimentation of the Sedimentation, New York, 10.1061/9780784408230.

Vives, S. P. (1990). Nesting ecology and behavior of hornyhead chub Nocomis-Biguttatus, a keystone species in Allequash-Creek, Wisconsin. The American Midland Naturalist, 124(1), 46. https://doi.org/10.2307/2426078

Volkenborn, N., Polerecky, L., Wethey, D. S., \& Woodin, S. A. (2010). Oscillatory porewater bioadvection in marine sediments induced by hydraulic activities of Arenicola marina. Limnology and Oceanography, 55(3), 1231-1247. https://doi.org/10.4319/ lo.2010.55.3.1231

Volkenborn, N., \& Reise, K. (2006). Lugworm exclusion experiment: Responses by deposit feeding worms to biogenic habitat transformations. Journal of Experimental Marine Biology and Ecology, 330(1), 169-179. https://doi.org/10.1016/j.jembe.2005.12.025

Wallin, J. E. (1992). The symbiotic nest association of yellowfin shiners, Notropis-Lutipinnis, and bluehead chubs, Nocomis-Leptocephalus. Environmental Biology of Fishes, 33(3), 287-292. https://doi.org/10.1007/Bf00005872

Wilcock, P. R., \& Crowe, J. C. (2003). Surface-based transport model for mixed-size sediment. Journal of Hydraulic Engineering-Asce, 129(2), 120-128. https://doi.org/10.1061/(Asce)0733-9429(2003)129:2(120)

Wooster, J. K., Dusterhoff, S. R., Cui, Y. T., Sklar, L. S., Dietrich, W. E., \& Malko, M. (2008). Sediment supply and relative size distribution effects on fine sediment infiltration into immobile gravels. Water Resources Research, 44, W03424. https://doi.org/10.1029/ 2006WR005815 
Yager, P. L., Nowell, A. R. M., \& Jumars, P. A. (1993). Enhanced deposition to pits-a local food source for benthos. Journal of Marine Research, 51(1), 209-236. https://doi.org/10.1357/0022240933223819

Zimmermann, A. E., \& Lapointe, M. (2010). Intergranular flow velocity through salmonid redds: Sensitivity to fines infiltration from low intensity sediment transport events. River Research \& Applications, 21(8), 865-881. https://doi.org/10.1002/rra.856 